OPEN ACCESS

Edited by:

Haiwei Luo,

The Chinese University of Hong Kong,

China

Reviewed by:

Pierre Cornelis,

Vrije Universiteit Brussel, Belgium

Katherine Barbeau,

University of California, San Diego,

United States

Simon Colin Andrews,

University of Reading,

United Kingdom

*Correspondence.

Arkadiy I. Garber

arkadiyg@usc.edu

rkdgarber@gmail.com

Nancy Merino

nmerino@elsi.jp

†Present address:

Arkadiy I. Garber

Division of Biological Sciences,

University of Montana, Missoula, MT,

United States

Specialty section:

This article was submitted to

Evolutionary and Genomic

Microbiology,

a section of the journal

Frontiers in Microbiology

Received: 20 September 2019

Accepted: 09 January 2020

Published: 31 January 2020

Citation:

Garber Al, Nealson $\mathrm{KH}$,

Okamoto A, McAllister SM, Chan CS, Barco RA and Merino N (2020)

FeGenie: A Comprehensive Tool

for the Identification of Iron Genes and Iron Gene Neighborhoods

in Genome and Metagenome

Assemblies. Front. Microbiol. 11:37.

doi: 10.3389/fmicb.2020.00037

\section{FeGenie: A Comprehensive Tool for the Identification of Iron Genes and Iron Gene Neighborhoods in Genome and Metagenome Assemblies}

\author{
Arkadiy I. Garber,2*t, Kenneth H. Nealson ${ }^{1}$, Akihiro Okamoto ${ }^{3}$, Sean M. McAllister ${ }^{4}$, \\ Clara S. Chan ${ }^{2,4}$, Roman A. Barco ${ }^{1}$ and Nancy Merino ${ }^{1,5,6 *}$ \\ ${ }^{1}$ Department of Earth Sciences, University of Southern California, Los Angeles, CA, United States, ${ }^{2}$ Department of Earth \\ Sciences, University of Delaware, Newark, DE, United States, ${ }^{3}$ International Center for Materials Nanoarchitectonics, \\ National Institute for Materials Science, Tsukuba, Japan, ${ }^{4}$ School of Marine Science and Policy, University of Delaware, \\ Newark, DE, United States, ${ }^{5}$ Earth-Life Science Institute, Tokyo Institute of Technology, Tokyo, Japan, ${ }^{6}$ Biosciences \\ and Biotechnology Division, Lawrence Livermore National Laboratory, Livermore, CA, United States
}

Iron is a micronutrient for nearly all life on Earth. It can be used as an electron donor and electron acceptor by iron-oxidizing and iron-reducing microorganisms and is used in a variety of biological processes, including photosynthesis and respiration. While it is the fourth most abundant metal in the Earth's crust, iron is often limiting for growth in oxic environments because it is readily oxidized and precipitated. Much of our understanding of how microorganisms compete for and utilize iron is based on laboratory experiments. However, the advent of next-generation sequencing and surge in publicly available sequence data has made it possible to probe the structure and function of microbial communities in the environment. To bridge the gap between our understanding of iron acquisition, iron redox cycling, iron storage, and magnetosome formation in model microorganisms and the plethora of sequence data available from environmental studies, we have created a comprehensive database of hidden Markov models (HMMs) based on genes related to iron acquisition, storage, and reduction/oxidation in Bacteria and Archaea. Along with this database, we present FeGenie, a bioinformatics tool that accepts genome and metagenome assemblies as input and uses our comprehensive HMM database to annotate provided datasets with respect to iron-related genes and gene neighborhood. An important contribution of this tool is the efficient identification of genes involved in iron oxidation and dissimilatory iron reduction, which have been largely overlooked by standard annotation pipelines. We validated FeGenie against a selected set of 28 isolate genomes and showcase its utility in exploring iron genes present in 27 metagenomes, 4 isolate genomes from human oral biofilms, and 17 genomes from candidate organisms, including members of the candidate phyla radiation. We show that FeGenie accurately identifies iron genes in isolates. Furthermore, analysis of metagenomes using FeGenie demonstrates that the 
iron gene repertoire and abundance of each environment is correlated with iron richness. While this tool will not replace the reliability of culture-dependent analyses of microbial physiology, it provides reliable predictions derived from the most up-to-date genetic markers. FeGenie's database will be maintained and continually updated as new genes are discovered. FeGenie is freely available: https://github.com/Arkadiy-Garber/FeGenie.

Keywords: hidden Markov model (HMM) database, iron transport, iron storage, iron oxidation, iron reduction, iron gene regulation, magnetosome, siderophore

\section{INTRODUCTION}

Iron is the fourth most abundant element in the Earth's crust (Morgan and Anders, 1980), where it occurs primarily as ferrous $[\mathrm{Fe}(\mathrm{II})]$ or ferric [Fe(III)] iron. Under circumneutral $\mathrm{pH}$ and aerobic conditions, ferrous iron spontaneously oxidizes to its ferric form, which precipitates and settles out of solution becoming highly limiting to microbial life (Emerson, 2016). Nonetheless, microorganisms have evolved mechanisms to deal with this limitation, as evidenced by the variety of known enzymes responsible for iron scavenging (Barry and Challis, 2009), transport (Wyckoff et al., 2006; Toulza et al., 2012; Fillat, 2014; Lau et al., 2016), and storage (Smith, 2004; Rivera, 2017). While iron is limiting in many natural ecosystems, environments exist where iron concentrations are high enough to support communities of microorganisms capable of deriving energy from iron oxidation (Emerson and Moyer, 2002; Jewell et al., 2016). These environments can also be inhabited by microorganisms capable of using ferric iron, usually in the form of a mineral, as a terminal electron acceptor in electron transport chains (Gao et al., 2006; Emerson, 2009; Elliott et al., 2014; Quaiser et al., 2014). While various marker genes, based on the study of a few model organisms, have been inferred, relatively little is known about the genetics behind iron oxidation and reduction (He et al., 2017).

Microbial iron metabolisms (Figure 1) and acquisition/transport pathways (Figure 2) play significant roles across a wide range of environments. Indeed, the prevalence of iron as a necessary cofactor (Ayala-Castro et al., 2008) and the dependence of life on iron, with the exception of a group of homolactic bacteria (Pandey et al., 1994), suggests that life evolved in an iron-rich world. Moreover, the variety of microorganisms in the archaeal and the bacterial domains capable of using iron as an electron donor or acceptor (Nealson and Saffarini, 1994; Weiss et al., 2007; Hedrich et al., 2011; Ilbert and Bonnefoy, 2013; Fullerton et al., 2017) suggests that these metabolisms were either adopted very early in the history of life or benefited from horizontal gene acquisition. There are examples of organisms that are considered "iron-free" and do not appear to encode genes associated with iron homeostasis, such as Borrelia burgdorferi (Andrews et al., 2003) and Treponema pallidum (Posey and Gherardini, 2000). However, as pointed out by Andrews et al. (2003), since these Bacteria are intracellular parasites, their genomes are small $(\sim 1 \mathrm{Mbp})$ and encode only a subset of genes required for bacterial growth and survival; reliance on host iron-dependent metabolic processes likely resulted in these parasites losing iron-associated genes.

Over the past few decades, almost three hundred genes involved in iron transport, metabolism, and transformation of iron and iron-containing minerals (e.g., magnetite, hematite, ferrihydrite, olivine, etc.) have been identified. Only a small proportion of these genes are thought to be involved in dissimilatory iron reduction and the energy-deriving process of iron oxidation. These are generally not annotated as such by established gene annotation pipelines, such as RAST (Overbeek et al., 2014), GhostKOALA (Kanehisa et al., 2016), MAPLE (Arai et al., 2018), and InterProScan (Quevillon et al., 2005). There are also no publicly available hidden Markov models (HMMs) for genes involved in iron oxidation and reduction, with the exception of $m t r B$ (TIGR03509) and $m t r C$ (TIGR03507), which have HMMs available within the TIGRFAMS HMM database. Moreover, many iron-related gene operons contain genes that are not exclusive to iron metabolism, but, nonetheless, within that operon, play an important role in acquiring or transporting iron (e.g., $a s b C$ in the siderophore synthesis gene operon as $b A B C D E F$ is annotated as an AMP-binding enzyme by the Pfam database). Herein, we make a publicly available set of HMMs based on current knowledge of iron acquisition, storage and respiratory oxidation/reduction mechanisms, and integrate that with HMMs based on all available genetic markers for iron acquisition, storage, and redox cycling in Bacteria and Archaea.

We present FeGenie, a new bioinformatics tool that comes with a curated and publicly available database of profile HMMs for enzymes involved in iron acquisition, storage, and redoxcycling in prokaryotes. FeGenie is available as a command-line tool, installed manually or via Conda configuration ${ }^{1}$. Users can submit genomes and metagenomes (in the form of contigs, amino acid gene sequences, or GenBank format files) for identification of known iron-related pathways. FeGenie consists of 208 protein families representing 12 iron-related functional categories (summarized in Table 1 and Supplementary Table S1). These functions are distributed across five overarching categories: iron acquisition/transport, iron storage, iron gene regulation, iron redox reactions, and magnetosome formation. HMMs were either manually constructed or taken from Pfam/TIGRFAMS. The advantage of using HMMs, as compared to local sequence alignments, is the rapid and sensitive identification of distantly related homologs to genes of interest (Eddy, 2004). This is

\footnotetext{
${ }^{1}$ https://conda.io/projects/conda/en/latest/
} 

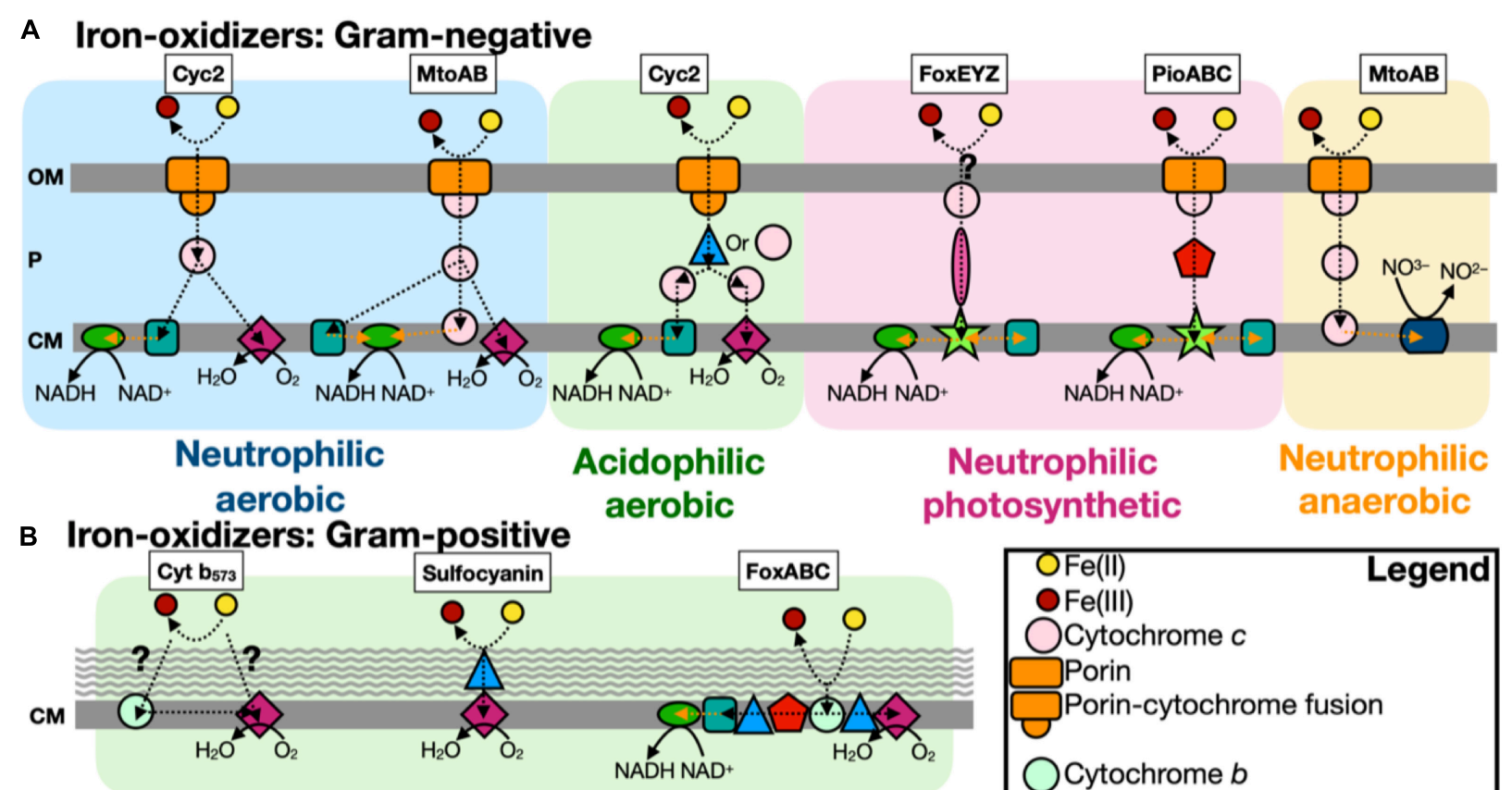

c Iron-reducers (anaerobic)

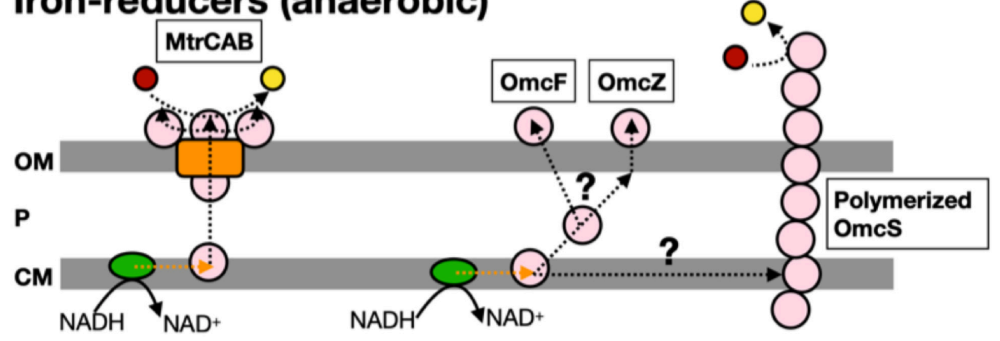

OFe(II)
OFe(III)
Cytochrome $c$
Porin
Porin-cytochrome fusion
Cytochrome $b$
NADH dehydrogenase
Quinone pool
bc1 complex
Terminal oxidase
Photosynthetic reaction center
Copper protein
Iron-sulfur protein
Nitrate reductase
Pyrroloquinoline quinone protein

FIGURE 1 | Scheme of known iron-oxidizers and iron-reducers. There are several different types of iron-oxidizers known, with more information on Gram-negative (A) bacteria compared to Gram-positive (B) bacteria (note: the acidophilic aerobic iron-oxidizers can use either a copper protein or cytochrome $c$ to transfer electrons in the periplasm). (C) For iron-reducers, there are only two mechanisms known and under anaerobic conditions. The genes identified by FeGenie are in boxes above each type, with the exception of Cyt b573, which has yet to be confirmed for iron oxidation (White et al., 2016). FeGenie does not include pili and flavin-related genes since these genes are commonly associated with other functions/metabolisms. Modified from White et al. (2016) and Wang et al. (2019). OM, outer membrane; P, periplasm; and CM, cytoplasmic membrane.

particularly important in the analysis of large environmental datasets with uncultivated and/or novel microorganisms.

To validate FeGenie, we tested the program against 28 microbial genomes (Supplementary Table S2) with established pathways for iron acquisition, iron oxidation, and iron reduction. These genomes are comprised of model organisms, including siderophore-producers, magnetotactic bacteria, ironreducers, as well as known and suspected iron-oxidizers. We demonstrate that this tool efficiently identifies iron-related genes and potential operons present within selected representative genomes, accurately identifying iron oxidation and reduction genes in known and potential iron-oxidizers and iron-reducers, respectively. FeGenie was also used to analyze members of the recently discovered Candidate Phyla Radiation (CPR) (Brown et al., 2015) and other candidate taxa, as well as 27 publiclyavailable metagenomes, representative of a range of habitats that include iron-rich and iron-poor marine and terrestrial systems (Table 2). We present the results of these analyses and establish
FeGenie as a straightforward and simple tool for the identification of iron-related pathways in genomes and metagenomes.

\section{MATERIALS AND METHODS}

\section{Algorithm Overview}

FeGenie is implemented in Python 3, with three required dependencies: HMMER v. 3.2.1 (Johnson et al., 2010), BLASTp v. 2.7.1 (Madden, 2013), and Prodigal v. 2.6.3 (Hyatt et al., 2010). External installation of these dependencies is not required if FeGenie is configured using Conda ${ }^{2}$. There are two optional dependencies, which must be installed externally: $R$ ( $\mathrm{R}$ Core Team, 2013) and Rscript (R Core Team, 2013). R packages used in FeGenie include argparse (Davis, 2018), ggplot2 (Wickham, 2009), ggdendro (de Vries and Ripley, 2016), reshape (Wickham,

\footnotetext{
${ }^{2}$ https://conda.io/projects/conda/en/latest/
} 


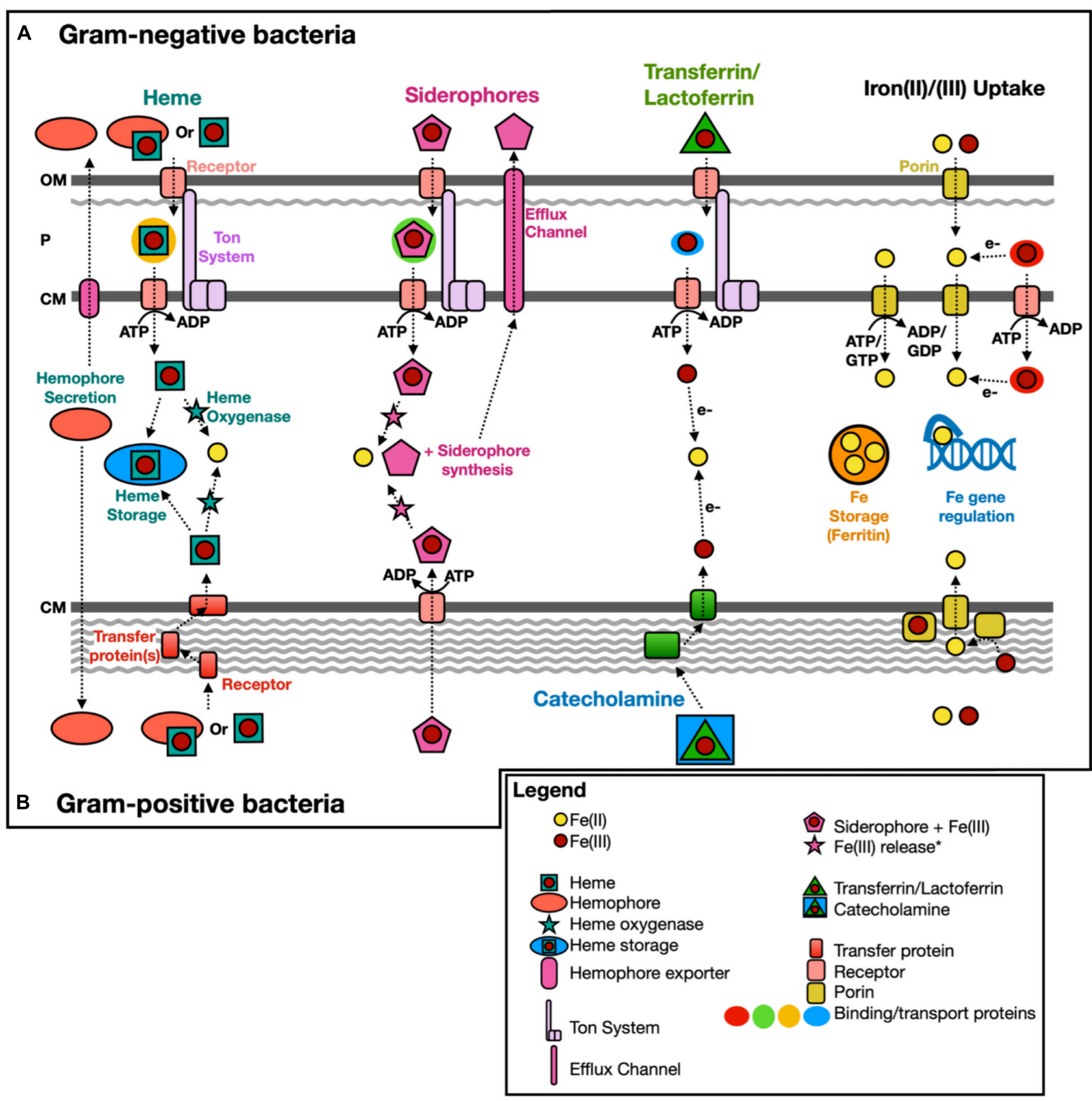

FIGURE 2 | Scheme of known iron acquisition, storage, and regulation pathways. Gram-negative (A) and Gram-positive (B) bacteria have different mechanisms to uptake iron due to differences in the cell membrane structure. Iron(II)/(III) uptake can also be mediated extracellularly by redox cycling secondary metabolites, such as phenazine-1-carboxylic acid (Cornelis and Dingemans, 2013). OM, outer membrane; P, periplasm; and CM, cytoplasmic membrane. Modified from Anzaldi and Skaar (2010); Caza and Kronstad (2013), Contreras et al. (2014); Kranzler et al. (2014), Lau et al. (2016). *Fe(III) release from siderophores intracellularly could include Fe(III) reduction (e.g., fpvG, Ganne et al., 2017) or modification/hydrolysis of the siderophore (e.g., esterase, Brickman and Mclntosh, 1992).

2007), reshape2 (Wickham, 2007), grid (R Core Team, 2013), ggpubr (Kassambara, 2017), tidyverse (Wickham, 2017), and Pvclust (Suzuki and Shimodaira, 2006); users need to install these packages independently using Rscript (detailed instructions on this are available within the FeGenie Wiki ${ }^{3}$ ). The overall workflow of FeGenie is outlined in Figure 3. User-provided input to this program includes a folder of genomes or metagenomes, which must all be in FASTA format, comprised of contigs or scaffolds. Users can also submit amino acid gene sequences

${ }^{3}$ https://github.com/Arkadiy-Garber/FeGenie/wiki/Installation in FASTA or GenBank format. First, Prodigal (Hyatt et al., 2010) is used to predict open-reading frames (ORFs). A custom library of profile HMMs (library described in section "HMM Development: Building and Calibrating HMMs") is then queried against these ORFs using hmmsearch (Johnson et al., 2010), with custom bit score cutoffs for each HMM. Additionally, genes shown to be involved in dissimilatory iron reduction but lacking sufficient homologs in public repositories (precluding us from building reliable HMMs) are queried against the user-provided dataset using BLASTp (Madden, 2013) with a default e-value cutoff of $1 \mathrm{E}-10$. These genes include the S-layer 
TABLE 1 | Summary of iron-related protein families that are represented as pHMMs in FeGenie.

\begin{tabular}{|c|c|c|}
\hline Category & Function & Protein Families \\
\hline \multirow[t]{6}{*}{ Iron acquisition } & Iron(II)/(III) transport & EfeuOB ${ }^{1}$, FbpABC $^{2}$, SfuABC $^{3}$, YfuABC $^{4}$, FeoAB(C) $^{5}$, FutA1 $^{6}$, FutA2 $^{6}$, FutB $^{6}$, FutC $^{6}$, YfeABCD $^{7}$ \\
\hline & Heme oxygenase & 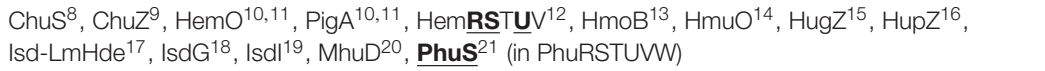 \\
\hline & Heme transport & 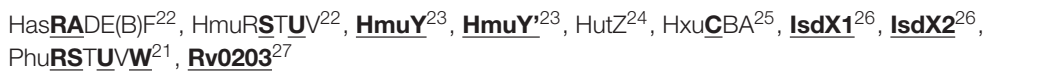 \\
\hline & Transferrin/Lactoferrin & $\operatorname{Tbp} \underline{\mathbf{A B}}(\mathrm{Lbp} \underline{\mathbf{A} B})^{28}, \mathrm{Sst} \underline{\mathbf{A B}} \mathrm{CD} D^{29}$ \\
\hline & Siderophore synthesis & 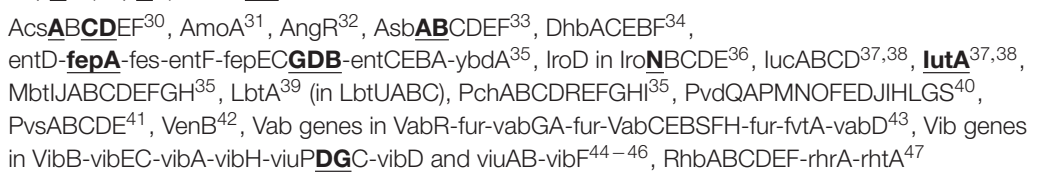 \\
\hline & Siderophore transport & 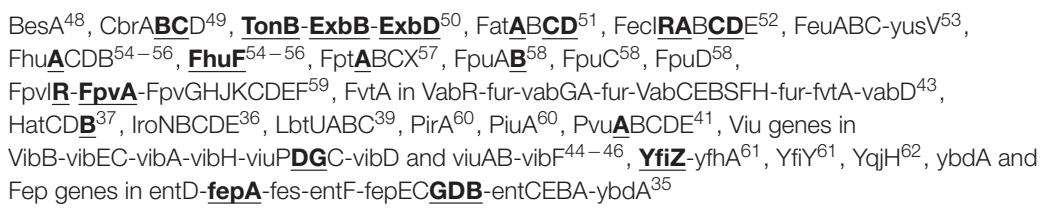 \\
\hline Iron Gene regulation & Transcriptional regulation & $\begin{array}{l}\underline{\text { DtxR }}^{63}, \text { FecR (in FeclRABCDE) } \\
\text { RhbABCDEF-rhrA-rhtA } \\
\text { FeoC }\end{array}$ \\
\hline \multirow{4}{*}{$\begin{array}{l}\text { Iron oxidation and } \\
\text { reduction }\end{array}$} & Iron oxidation & Cyc1 $^{66,67}$, Cyc2 $^{66,67,68}$, FoxABC $^{69}$, FoxEYZ $^{70}$, Sulfocyanin $^{71}$, PioABC $^{72}$ \\
\hline & $\begin{array}{l}\text { Probable iron oxidation and } \\
\text { possible iron reduction }\end{array}$ & MtoA $\underline{\mathbf{B}}^{73}$, Cyc2 (cluster 3) \\
\hline & Dissimilatory iron reduction & $\begin{array}{l}\text { CymA }^{74}, \text { Mtr } \underline{\mathbf{C}} \underline{B}^{75}, \mathrm{OmcF}^{76}, \mathrm{OmcS}^{76}, \mathrm{OmcZ}^{76}, \mathrm{FmnA}^{2} \text { dmkA-fmnB-pplA-ndh2-eetAB-dmkB } \\
\text { DFE_0448-0451, DFE_0461-0465 }\end{array}$ \\
\hline & Probable iron reduction & MtrCB, MtrAB, MtoAB-MtrC \\
\hline Iron storage & Iron storage & $\underline{B f r}^{79}, \underline{\text { DpsA }}^{80}, \underline{\mathbf{F t n}}^{81}$ \\
\hline Magnetosome-related & Magnetosome formation & $\begin{array}{l}\text { MamABEKLMOPQ }{ }^{82,83} \text { (Note: These genes are found in all known magnetotactic microorganisms, } \\
\text { except for mamL which is found in magnetite-producing magnetotactic microorganisms }{ }^{81} \text { ) }\end{array}$ \\
\hline
\end{tabular}

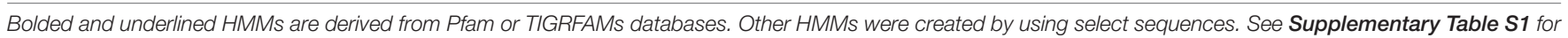

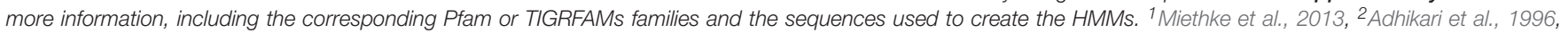

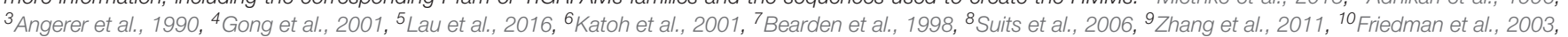

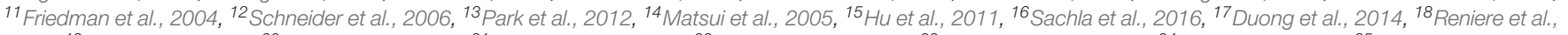

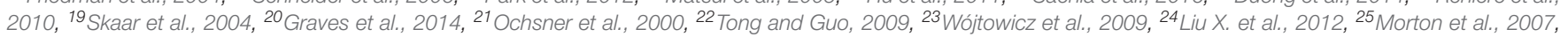

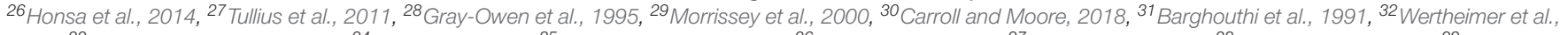

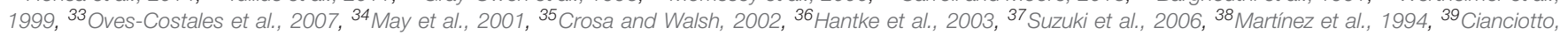

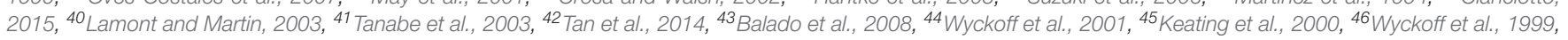

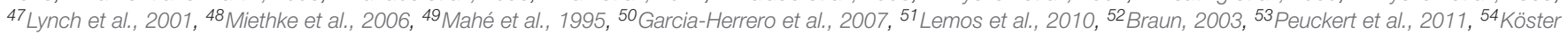

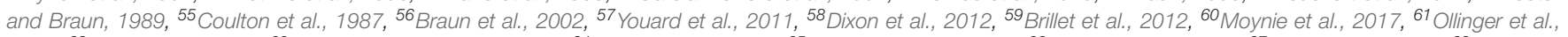

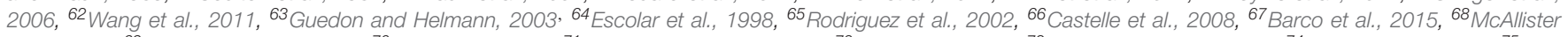

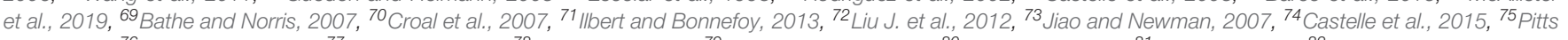

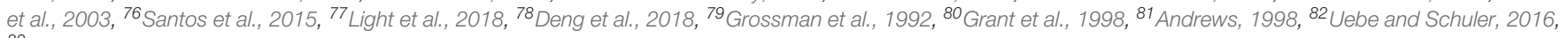
83 Kolinko et al., 2016.

proteins implicated in iron reduction in Thermincola potens JR (Carlson et al., 2012), as well as porin-cytochrome encoding operons implicated in iron reduction in Geobacter spp. (Shi et al., 2014). The results of hmmsearch (Johnson et al., 2010) and BLAST (Madden, 2013) are then analyzed and candidate gene neighborhoods identified. Potential for dissimilatory iron oxidation and reduction is determined based on a set of rules that are summarized in Supplementary Table S3. Even though the sensitivity of each HMM has been calibrated against NCBI's nr database (see section "HMM Development: Building and Calibrating HMMs" for details on the calibration process), we recommend that users take advantage of an optional cross-validation feature of the program that allows users to search each FeGenie-identified putative iron gene against a user chosen database of reference proteins (e.g., NCBI's nr, RefSeq). Based on these analyses, FeGenie outputs the following files:

1. CSV file summarizing all identified putative iron-related genes, their functional category, bit score (shown in the context of the calibrated bit score cutoff of the matching HMM), number of canonical heme-binding motifs, amino acid sequence, and closest homolog to a user-provided database (optional; e.g., NCBI nr database).

2. Heatmap summary comparing the number of genes identified from each iron-related category across the analyzed genomes/metagenomes.

3. Three plots created with Rscript (optional): (1) Dendrogram showing the dissimilarity (based on iron-gene distributions) between provided genomes or assemblies, 
TABLE 2 | Summary of metagenomes analyzed.

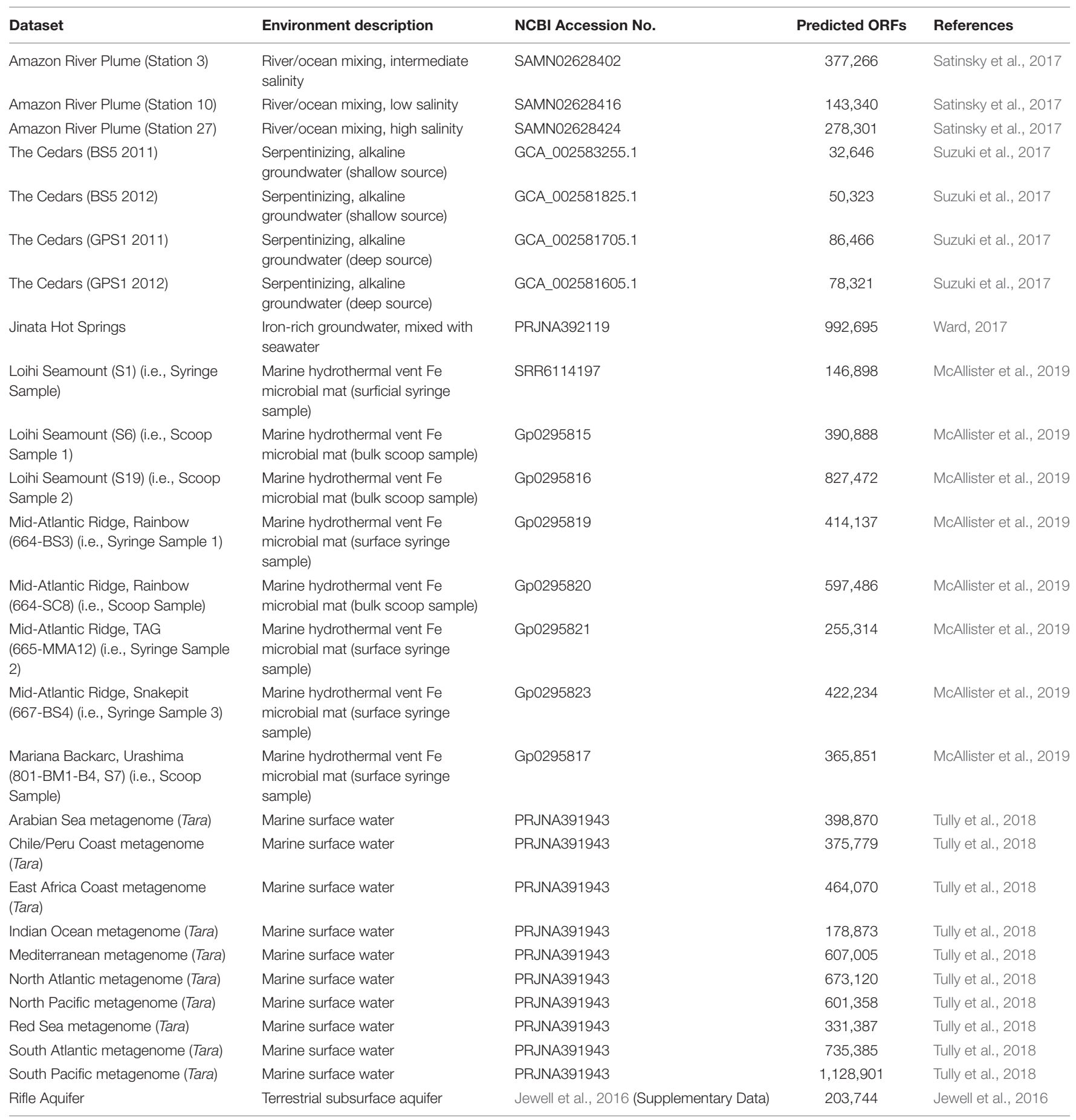

The list of 27 previously published metagenomes, representing a wide range of habitats from iron-rich to iron-poor marine and terrestrial systems. Prodigal v. 2.6.3 (Hyatt et al., 2010) was used to predict the number of open reading frames (ORFs) in each metagenome dataset. See section "Acquisition and assembly of environmental metagenomes" in the Materials and Methods for more detailed description and acquisition.

(2) scaled heatmap based on the relative distribution of iron-related genes across genomes/metagenomes, and (3) dot plot showing the relative abundance of iron genes across genomes. Using the $\mathrm{R}$ package Pvclust (Suzuki and Shimodaira, 2006), the dendrogram is produced using Ward's method and Euclidian distance metric to hierarchically cluster the data with bootstrapped probability values for each cluster. This will allow users to assess the uncertainty in clustering, given that the analyzed genomes and metagenomes may not necessarily be 


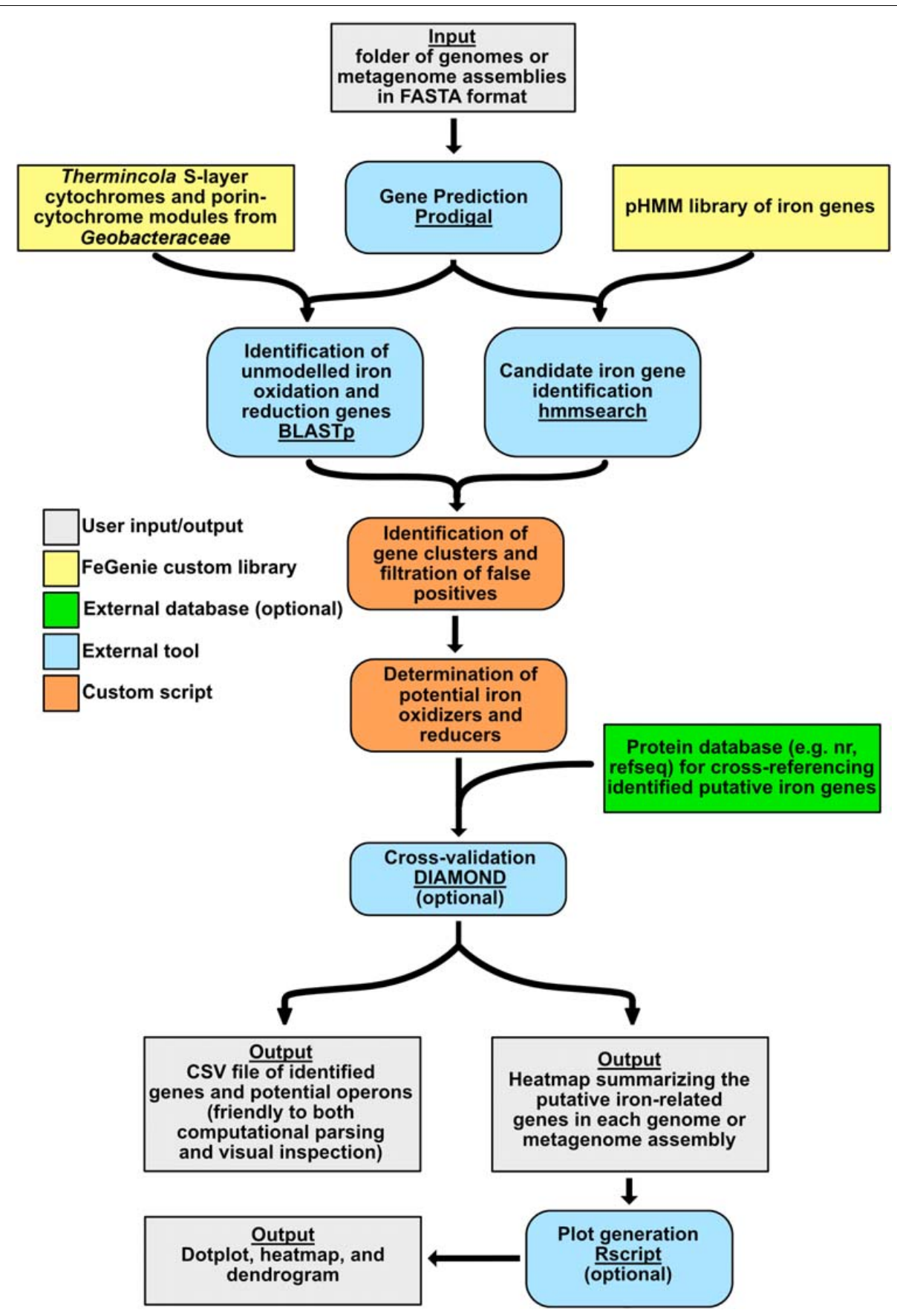

FIGURE 3 | FeGenie algorithm overview. Color-coded to represent various aspects of the program, including external programs/dependencies, optional databases for cross-reference, and custom Python scripts.

derived from extremely different environments and iron/ redox regimes.

\section{HMM Development: Building and Calibrating HMMs}

Collection of iron-related protein sequences occurred between May 2018 and August 2019. FeGenie's HMM library includes genes associated with iron acquisition from the environment, iron storage, magnetosome formation, and iron redox-cycling. This tool does not include genes related to downstream iron utilization pathways, such as a heme and iron-sulfur cluster synthesis. Moreover, FeGenie's HMM library does not include genes associated with small regulatory RNAs. Sequences corresponding to proteins whose functions have been characterized in the literature were downloaded from reviewed 
sequences on UniProtKB (The UniProt Consortium, 2017) or NCBI, excluding proteins that were already represented by Pfam families (Finn et al., 2016) (Supplementary Table S1). To expand the diversity of each of the collected proteins, those sequences were then used as queries in a BLASTp v.2.6.0 (Madden, 2013) search against NCBI's RefSeq (Release 89) database (Pruitt et al., 2007), with a minimum amino acid identity cutoff of $35 \%$ (Rost, $1999)$ over at least $70 \%$ of the query length. These search results were then de-replicated so that each seed sequence is represented by a unique set of non-overlapping BLAST hits. Using MMseqs 2 (Steinegger and Söding, 2017), each seed sequence and its set of BLAST hits were then collapsed with a $70 \%$ amino acid identity cutoff to remove overrepresented protein sequences, which would otherwise create biases in resulting HMMs. Each collapsed set of sequences was then aligned using Muscle v.3.8.31 (Edgar, 2004) and each alignment was manually inspected and curated. These curated alignments were then used as seeds for the generation of HMMs using the hmmbuild command from HMMER (Johnson et al., 2010). To calibrate appropriate bit score cutoffs for each HMM in the HMM library, each HMM was queried against NCBI's nr database (Pruitt et al., 2007) using hmmsearch. By manually inspecting each hmmsearch result, we identified bit score cutoffs that optimally delineated between true and false positives among hits from nr. Thus, each HMM in the FeGenie library received its own custom bit score cutoff. This library represents the most comprehensive set of proteins associated with iron metabolisms and pathways available at the time of collection. This database will be updated as new genes relevant to iron are discovered.

\section{HMM Development: Iron Oxidation/Reduction}

For determination of iron oxidation potential, we included the candidate iron oxidase from acidophilic and neutrophilic iron-oxidizing bacteria, Cyc2 (Barco et al., 2015). As shown by McAllister et al. (2019), Cyc2 is represented by three phylogenetically distinct clusters; thus, we constructed three different HMMs, specific to each cluster. Cluster 1 includes sequences from most known, well-established neutrophilic ironoxidizers but is yet to be genetically or biochemically verified as an iron oxidase. Clusters 2 and 3 include sequences from acidophilic iron-oxidizing bacteria, including two homologs that have been biochemically verified to catalyze the oxidation of iron: Cyc2 from Acidithiobacillus ferrooxidans (Castelle et al., 2008) and Cyt572 from Leptospirillum rubarum (Jeans et al., 2008).

FeGenie also includes MtoA as a possible, but as yet unconfirmed, indicator for iron oxidation potential (Liu J. et al., 2012). The function of MtoA is unclear since it is homologous to the iron-reducing enzyme, MtrA, of Shewanella oneidensis MR-1, but nonetheless it is proposed to be involved in iron oxidation by Liu J. et al. (2012), even though there is a lack of supporting gene expression data. Indeed, MtoA has been shown to rescue $\Delta m t r A$ mutants of MR-1, partially recovering the ability to reduce ferric iron (Liu J. et al., 2012). Nonetheless, phylogenetic analysis shows a separation between the mtrA genes utilized by known ironreducing bacteria (particularly within the Alteromonadaceae and
Vibrionaceae families), and $m$ toA homologs encoded by known and suspected iron-oxidizing bacteria (Garber, 2018), including members of the Gallionellaceae (Supplementary Figure S1). Thus, two separate HMMs were constructed, one for MtrA homologs encoded by known iron-reducers and one for MtoA homologs encoded by known and suspected iron-oxidizers. The MtoA HMM includes PioA, which has been genetically (Jiao and Newman, 2007) and experimentally (Gupta et al., 2019) verified to be necessary for iron oxidation in Rhodopseudomonas palustris TIE-1. Moreover, the mtrA-encoding operon in ironreducing bacteria typically encodes $m \operatorname{tr} C$, an outer-membrane cytochrome thought to participate in dissimilatory iron reduction (Lower et al., 2007). MtrC is not encoded by iron-oxidizing bacteria (Shi et al., 2014), supporting its use as an additional indicator for iron-reducing potential. In light of these ambiguities in the function of MtoA, identification of MtoAB by FeGenie is treated with caution as a potential iron oxidase/reductase. Other HMMs used for determination of iron oxidation potential include genes from iron-oxidizing Archaea: sulfocyanin (Castelle et al., 2015), foxABC (Bathe and Norris, 2007), and foxEYZ (Croal et al., 2007).

Determination of iron reduction potential is dependent on the identification of homologs to various porin-cytochrome operons, including $m \operatorname{tr} C A B$ (Pitts et al., 2003), as well as two operons from Desulfovibrio ferrophilus (Deng et al., 2018), various porincytochrome operons identified in Geobacteraceae (Shi et al., 2014), and genes encoding S-layer-associated proteins implicated in iron reduction in Thermincola potens JR (Carlson et al., 2012). Additionally, we included the flavin-dependent operon that was implicated in iron reduction in Listeria monocytogenes (Light et al., 2018).

Seed sequences for MtrA, MtoA, and Cyc2 were manually curated, aligned using Muscle, and used for the building of HMMs. Due to the highly divergent nature of the porin domain in $\mathrm{Cyc} 2$, identification of $\mathrm{Cyc} 2$ is dependent upon the presence of a heme-binding motif and length of at least 375 amino acids, which is considered long enough to encode an outer membrane porin (Tamm et al., 2004).

\section{HMM Development: Siderophore Synthesis}

FeGenie can also be used to identify siderophore synthesis genes and potential operons. Siderophores are microbially produced products $(500-1200 \mathrm{Da})$ that have a preference for binding ferric iron (up to $10^{-53} \mathrm{M}$ ) (Ehrlich and Newman, 2008), enabling microorganisms to obtain this largely insoluble iron form. There are over 500 identified siderophores, categorized as catecholates, hydroxamates, or hydroxycarboxylic acids (Kadi and Challis, 2009). Microorganisms can synthesize siderophores via the NRPS (non-ribosomal peptide synthetase) or NIS (NRPS-independent siderophore) pathways (Carroll and Moore, 2018). The NRPSs are megaenzymes that consist of modular domains (adenylation, thiolation, and condensation domains) to incorporate and sequentially link amino acids, keto acids, fatty acids, or hydroxy acids (Gulick, 2017). The NRPSs are highly selective and predictable based on the product produced, and 
FeGenie will identify these putative siderophore synthesis genes based on the genomic proximity of each identified gene (Table 1). In contrast, the NIS pathway consists of multiple enzymes that each have a single role in the production of a siderophore, such as aerobactin, which was the first siderophore discovered to be synthesized by this pathway (Kadi and Challis, 2009). The operon involved in aerobactin biosynthesis is iucABCD, and homologs of the genes iucA and iucC (which are included in FeGenie) are indicators of siderophore production via the NIS pathway (Carroll and Moore, 2018). The HMM library that represents siderophore synthesis consists of HMMs derived from the Pfam database, as well as those constructed here (Table 1). Because many different siderophore synthesis pathways share homologous genes, we developed HMMs that were sensitive to the entirety of each gene family, rather than for each individual siderophore. Supplementary Data Sheet S1 summarizes the gene families from which HMMs were built and includes gene families for siderophore export, iron uptake and transport, and heme degradation. Although FeGenie cannot predict the exact siderophore produced, FeGenie enables users to identify putative (and potentially novel) siderophore synthesis operons, which can then be confirmed by external programs, such as antiSMASH (Weber et al., 2015), a bioinformatics tool to identify biosynthetic gene clusters.

\section{HMM Development: Siderophore and Heme Transport}

Similar to siderophore synthesis, transport genes for siderophores, heme/hemophores, and iron from transferrin/lactoferrin are represented by HMMs specific to gene families. HMMs used by FeGenie to infer siderophore and heme transport include both custom-made and Pfam models (Table 1 and Supplementary Table S1). In Gram-positive bacteria, siderophores are delivered to an ATP-binding cassette (ABC) importer from a receptor protein (Brown and Holden, 2002) while hemes, hemophores, and iron from transferrin and lactoferrin are delivered via a receptor protein and a series of cell-wall chaperone proteins (Contreras et al., 2014). In comparison, for Gram-negative bacteria, the Ton system (TonBExbB-ExbD protein complex) is the commonly used transport mechanism located in the cytoplasmic membrane (Figure 2) (Krewulak and Vogel, 2011; Contreras et al., 2014). Because the Ton system can uptake other metabolites (e.g., vitamin B12), the identification of this transport pathway suggests only the potential for the transport of siderophores, hemes, and iron from transferrin/lactoferrin; it is the sole system known to transport these iron-bearing molecules, thus far, in Gram-negative bacteria (Faraldo-Gómez and Sansom, 2003; Caza and Kronstad, 2013). For example, Pseudomonas aeruginosa PAO1 encodes 34 different TonB-dependent receptors, including PiuA and PirA (Luscher et al., 2018). While this diversity of TonB-dependent receptors reflects, in part, an ability to uptake multiple types of siderophores, it also indicates that these receptors are also likely utilized for purposes outside of iron metabolism. Thus, it is possible that FeGenie overestimates the potential for the transport of iron-bearing compounds. In light of this potential for overestimation, caused by ambiguity related to the substrate targeted by TonB-dependent transport systems, we urge users to further investigate identified TonB-dependent receptors and not immediately interpret their presence as evidence of transport of siderophores, hemes, and/or iron from transferrin/lactoferrin.

\section{HMM Development: Iron Uptake}

FeGenie also features a set of genes implicated in the transport of ferrous and ferric iron ions. Some examples of these include futA1 and futA2 (Katoh et al., 2001), which bind both ferrous and ferric iron (Kranzler et al., 2014), although there is preference for Fe(II) (Koropatkin et al., 2007). Some iron transporters may also work in conjunction with the transport of heme, siderophore, or iron from transferrin/lactoferrin, such as the iron transport operon $E f e U O B$. Other genetic markers for iron transport encompassed by FeGenie's HMM library include feoABC (Lau et al., 2016), $f b p A B C$ (Adhikari et al., 1996), and others listed in Table 1 and Supplementary Table S1.

\section{HMM Development: Heme Transport and Lysis}

Heme oxygenase and transport genes define another strategy that microorganisms, especially pathogens, use to obtain iron from their environment. In particular, heme oxygenases enable pathogens to obtain iron from a host through oxidative cleavage of heme, thereby releasing iron (Wilks and Heinzl, 2014). Heme oxygenases are categorized into two groups: (1) "canonical" heme oxygenases (HmuO, PigA, and HemO), which degrade heme to biliverdin and carbon monoxide, and (2) "non-canonical" heme oxygenases (IsdG, IsdI, MhuD, and IsdLmHde), which degrade heme to products like staphylobilin (IsdG and IsdI) and mycobilin (MhuD) (Wilks and Heinzl, 2014). All these heme oxygenase genes are included in FeGenie's HMM library. Similarly, orthologs to known heme transport genes are also identified by FeGenie, including the five bacterial heme transport systems (Contreras et al., 2014): IsdX1, IsdX2, HasA, $\mathrm{HxuA}$, and Rv0203.

\section{HMM Development: Regulation}

Regulation of iron uptake and storage is an important aspect of iron homeostasis. Microorganisms often reside in everchanging conditions and must sense and respond to their outside environment with respect to iron transport. To this end, genes encoding transcriptional regulators modulate the expression of various genes relevant to iron acquisition. We included these genes in FeGenie's HMM library. These transcriptional regulators include FeoC, which functions as an iron sensor and repressor of the feo operon (Lau et al., 2016). Another important transcriptional regulator is ferric uptake regulator Fur, which binds ferrous iron and represses siderophore synthesis and iron uptake. Fur is also thought to control expression of genes involved in reactive oxygen species neutralization (Troxell and Hassan, 2013). Other regulators represented in FeGenie's HMM library include PchR (Heinrichs and Poole, 1996), DtxR (Brune et al., 2006), and YqjH (Wang et al., 2011). 
Extracytoplasmic-function (ECF) sigma factors are sensitive to signals from outside of the cell, and they bind and recruit RNA-polymerase to specific regions of the genome (Brooks and Buchanan, 2008). Two such ECF sigma factors, PvdS and Fpvi, are included in FeGenie's HMM library. PvdS controls expression of genes for pyoverdine biosynthesis, while FpvI controls expression of a TonB-dependent siderophore receptor (Reinhart and Oglesby-Sherrouse, 2016). In addition, we also included the FecR regulatory protein, which signals an (ECF) sigma factor to promote the expression of genes responsible for ferric citrate transport (Stiefel et al., 2001).

\section{Acquisition of Representative Genomes From RefSeq and Candidate Taxa}

Genome sequences were downloaded from the NCBI RefSeq and GenBank database (Pruitt et al., 2007) on November 4, 2017. Genomes from the Candidate Phyla Radiation and other candidate taxa were obtained using the NCBI accession IDs found in Hug et al. (2016). All NCBI accessions are listed in Supplementary Table S2, as well as Supplementary Data Sheets S2, S3, S10, S11.

\section{Acquisition and Assembly of Environmental Metagenomes}

- Loihi Seamount, Mid-Atlantic Ridge, and Mariana Backarc Iron microbial mats: Eight iron mat metagenomes, three from Loihi Seamount, four from the Mid-Atlantic Ridge, and one from the Mariana Backarc, were sequenced and assembled (details in McAllister et al., 2019). Syringe samples represent active samples from the edge of iron mats. Scoop and slurp samples represent bulk samples, which include deeper mat material. Assembly data available from JGI Sequence Project IDs Gp0295814Gp0295821 and Gp0295823.

- The Cedars, a terrestrial serpentinite-hosted system: Metagenome assemblies were downloaded from the NCBI GenBank database (BioProject Accession ID: PRJDB2971): GCA_002581605.1 (GPS1 2012), GCA_002581705.1 (GPS1 2011), GCA_002581825.1 (BS5 2012), and GCA_002583255.1 (BS5 2011) (Suzuki et al., 2017). GPS1 (Grotto Pool Springs) is sourced by deep groundwater while BS5 (Barnes Springs 5) is sourced by $\sim 15 \%$ deep groundwater and $\sim 85 \%$ shallow groundwater. Both environments host highly alkaline and highly reducing waters. Two samples were collected from each spring and represent temporal duplicates taken approximately 1 year apart. These metagenomes were processed as described in Suzuki et al. (2017).

- Amazon River plume estuary: Raw metagenome reads were downloaded from NCBI's Sequence Read Archive (SRA) corresponding to BioSamples SAMN02628402 (Station 3), SAMN02628424 (Station 27), and SAMN02628416 (Station $10)$; these correspond to samples taken along a salinity gradient formed as the Amazon River flows into the Atlantic Ocean (Satinsky et al., 2017). Station 10 represents water samples taken nearest to the source of river water, and Station 27 represents the sample taken furthest away from the river. Raw reads were quality trimmed using Trimmomatic v.0.36 (Bolger et al., 2014) with a sliding window of 4 base pairs (bp) and minimum average quality threshold of 15 (phred33) within that window; reads shorter than 36 bp were discarded. SPAdes v.3.10 (Bankevich et al., 2012) with the '-meta' flag (Nurk et al., 2017) and default k-mers was used for assembly of high-quality reads into contigs.

- Jinata Hot Springs: This metagenome assembly was provided by Dr. Lewis Ward and processed as described by Ward et al. (2019). The assembly is located in the NCBI database under accession PRJNA392119. Raw metagenome data are represented by accession numbers SRX4741377SRX4741380. This ecosystem represents a hot spring where low-oxygen and iron-rich fresh groundwater mixes with oxic and iron-deplete ocean water.

- Rifle Aquifer: ORFs from the assembled Rifle Aquifer metagenome were downloaded from the supplemental dataset published by Jewell et al. (2016).

- Tara Oceans: Assembled and published contigs corresponding to the fraction that was binned into draft genomes were originally processed and analyzed by Tully et al. (2018) and downloaded from Figshare ${ }^{4}$. This dataset represents a globally distributed set of marine metagenomes collected from the sunlit portion of the water column. The global distribution is defined by the Longhurst geographical provinces.

\section{RESULTS AND DISCUSSION}

\section{Validation of FeGenie Against Isolate Genomes}

We validated FeGenie by showing that it accurately identifies and classifies iron-related genes in representative organisms known to encode them. A total of 574 representative genomes from RefSeq were analyzed, and these results are provided in Supplementary Data Sheets S2, S3. Here, we present the results from a select set of 28 genomes (Supplementary Table S2 and Supplementary Data Sheets S4, S5), including known iron-oxidizers (e.g., Mariprofundus ferrooxydans PV-1 and Rhodopseudomonas palustris TIE-1), iron-reducers (e.g., Shewanella oneidensis MR-1 and Geobacter sulfurreducens PCA), magnetotactic bacteria (Magnetospirillum magneticum AMB-1), siderophore synthesis and uptake model microorganisms (e.g., Bacillus anthracis and Pseudomonas aeruginosa), and others (as listed in Supplementary Table S1). These genomes were chosen to showcase FeGenie's capacity to detect key genes relevant to the microbial iron-cycle (Figure 4).

Putative iron oxidation genes were detected in iron-oxidizing bacteria, including Sideroxydans lithotrophicus ES-1 (Emerson et al., 2013), Rhodobacter ferrooxidans SW2 (Croal et al., 2007), Mariprofundus ferrooxydans PV-1 (Emerson et al., 2007), Rhodopseudomonas palustris TIE-1 (Jiao et al., 2005), as well as

\footnotetext{
${ }^{4}$ http://dx.doi.org/10.6084/m9.figshare.5188273
} 


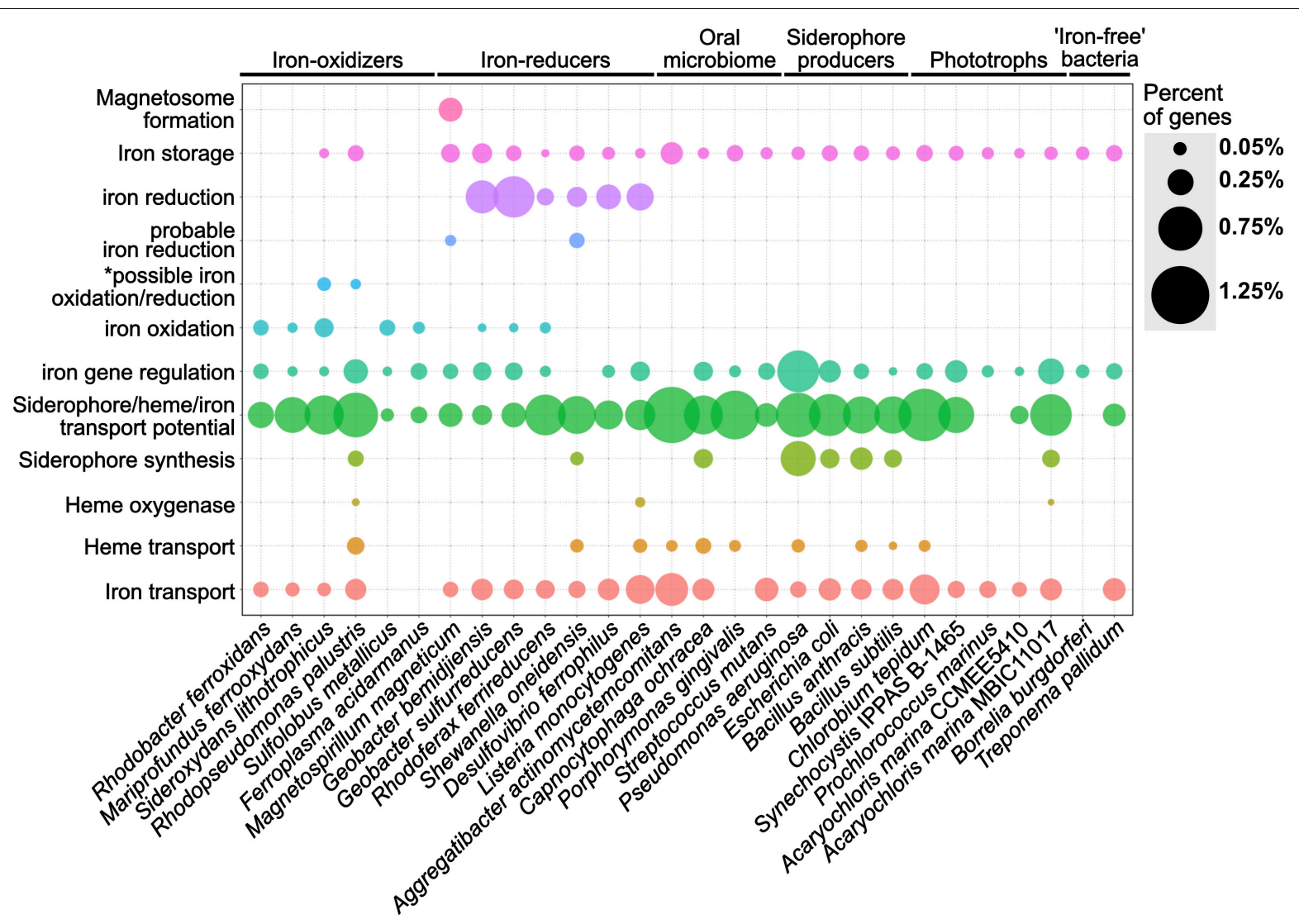

FIGURE 4 | Dot plot showing the relative abundance of different iron gene categories within 28 representative isolate genomes. The isolate genomes were selected as model microorganisms to demonstrate the accuracy of FeGenie for identifying genes involved in iron oxidation and reduction, iron transport (including siderophores and heme), iron storage, and iron gene regulation. The genomes were obtained from the NCBI RefSeq and GenBank databases and analyzed by FeGenie. The size of each dot reflects the number of genes identified for each category and normalized to the number of protein-coding genes predicted within each genome. ${ }^{*}$ This category is reserved for genes related to the mtoAB/pioAB gene family.

in Archaea, including Sulfolobus metallicus (Bathe and Norris, 2007) and Ferroplasma acidarmanus (Golyshina et al., 2000). S. lithotrophicus is a known iron-oxidizer and was found to encode $m t o A B$ (Liu J. et al., 2012) and three copies of cyc2 within its genome (Emerson et al., 2013). Since mtoAB are homologous to genes also implicated in iron reduction (mtrAB), FeGenie classified these genes as potentially related to iron oxidation or iron reduction (i.e., the "possible iron oxidation/reduction" category).

FeGenie accurately identified iron-reduction genes and operons in known iron-reducing bacteria. For example, Shewanella oneidensis MR-1, a model organism for iron reduction, was found to encode both copies of its porincytochrome module: $m \operatorname{tr} C A B$ and $m \operatorname{trDEF}$ ( $m \operatorname{trDEF}$ is homologous to $m \operatorname{tr} C A B$ and was identified as such by FeGenie). Additionally, FeGenie identified two more operons that each encode only $m \operatorname{tr} A B$, which FeGenie categorizes as "probable iron reduction" due to the lack of $m \operatorname{trC}$. Interestingly, within the mtrCABDEF operon, FeGenie also identified the ferrous iron transport genes $f e o A B$, which could be involved in the uptake of ferrous iron that is generated during iron reduction. This same operon also encodes a catalase (not included in FeGenie), which is a heme-containing protein that deals with oxidative stress and may potentially be expressed together with the iron-reduction genes to deal with the oxidative stress of high intracellular iron concentrations (Touati, 2000), likely resulting from dissimilatory iron reduction.

Some of the identified iron-reducers, for example, R. ferrireducens (Finneran et al., 2003), G. sulfurreducens (Lovley and Phillips, 1988) and G. bemidjiensis, also encode the cluster $3 c y c 2$, which FeGenie uses as a marker for iron oxidation. This gene has been confirmed as an iron-oxidase in Acidithiobacillus ferrooxidans (Castelle et al., 2008) and is also encoded by neutrophilic, obligate iron-oxidizers (Barco et al., 2015). We note that only one of these cluster 3-affiliated Cyc2 homologs, Cyt572, has been biochemically characterized and determined to have iron oxidase activity (Jeans et al., 2008). It is worth noting that Geobacter metallireducens has been previously shown to oxidize iron in a biological process known as nitrate-dependent iron oxidation (Weber et al., 2006) and does have a $c y c 2$ gene. Our results indicate that there are other Geobacter spp. that could also be involved in iron oxidation (either aerobically or anaerobically). 
Magnetospirillum magneticum AMB-1, a known magnetotactic bacterium (Matsunaga et al., 2005), was positive for magnetosome formation genes. $M$. magneticum AMB-1 also encodes $\operatorname{mtr} A B$ which FeGenie uses as a marker for "probable iron reduction." M. magneticum AMB-1 lacks the outer-membrane cytochrome (MtrC) that is always found within the $m \operatorname{tr} C A B$ operon of iron-reducing bacteria (Richardson et al., 2012; White et al., 2016). However, experimental evidence demonstrated that AMB-1 is an iron-reducing bacterium (Matsunaga et al., 2005). Without any other candidate iron reductases in AMB-1's genome, this indicates that $\mathrm{MtrAB}$ may be utilized in iron reduction without the outer-membrane component.

FeGenie was also used to identify iron acquisition and transport genes in model microorganisms, including siderophore transport and synthesis genes, heme transport and oxygenases, and $\mathrm{Fe}(\mathrm{II}) / \mathrm{Fe}$ (III) transport. It is worth noting that in these organisms not linked to respiratory iron oxidation or dissimilatory iron reduction, FeGenie did not identify genes related to these metabolisms. In Escherichia coli and Bacillus subtilis, FeGenie identified three genes that are necessary for the uptake of iron, efeUOB (Cao et al., 2007), in addition to other iron transport genes (Supplementary Data Sheet S4). Iron transport potential was also identified in nearly every genome analyzed (including the CPR, discussed more in the section "Case Study: Iron-related genes encoded within the Candidate Phyla Radiation and other Candidate Bacteria and Archaea"). This is expected, given that iron is a necessary micronutrient for the vast majority of life. As an example of FeGenie's capability to identify the siderophore gene families, we will focus on siderophore synthesis by Bacillus anthracis. $B$. anthracis is known to produce anthrabactin (bacACEBF) and petrobactin (asbABCDEF) (Oves-Costales et al., 2007). Both operons were correctly identified by FeGenie (Supplementary Data Sheet S5). Since the ORFs from each operon were annotated according to the gene family that each gene belongs to (Supplementary Data Sheet S1), users can cross-validate these genes with Supplementary Data Sheet S1 and confirm their identity through external pipelines. Further confirmation of these two operons by antiSMASH (Weber et al., 2015) (Supplementary Table S4) demonstrates the utility of FeGenie to identify siderophore synthesis gene operons.

Genes involved in heme transport and lysis were also identified in some of the model organisms. For example, in Pseudomonas aeruginosa PAO1, FeGenie identified hasA downstream to a TonB-dependent heme receptor. The rest of the has $A$ operon, however, was identified as part of the siderophore transport pathway. This is because some of the genes in the heme-transport operon hasRADEF are related to siderophore transport genes. This ambiguity in function demonstrates the weakness of FeGenie (and culture-independent, database-based approaches in general) and underscores the need to compare all identified putative iron-related genes against NCBI's nr or RefSeq databases to see the annotations associated with the closest homologs available in public repositories. This step will add additional confidence that a gene identified as iron-related is indeed so, based on its closest known annotated homolog.
Moreover, we stress the ambiguity presented by identification of TonB-dependent receptors. Although the TonB-dependent transport system is a commonly used mechanism in Gramnegative bacteria (Krewulak and Vogel, 2011; Contreras et al., 2014), as discussed in "Materials and Methods", this family of proteins could also be utilized for transport of a wide variety of substrates, many of which are irrelevant to iron homeostasis.

FeGenie identified iron-relevant genes encoded by five phototrophs, Chlorobium tepidum TLS, Synechocystis IPPAS B1465, Prochlorococcus marinus, and two strains of Acaryochloris marinus. As expected, the five analyzed phototrophs do not show genetic potential for iron oxidation or reduction. Generally, a higher number of genes related to iron and siderophore transport were identified in the anaerobic green-sulfur photoautotroph C. tepidum TLS, as compared to the freshwater and marine phototrophs, Synechocystis and Prochlorococcus, respectively. This may be due to the fact that $C$. tepidum performs anoxygenic photosynthesis in anaerobic, sulfide-rich niches (Eisen et al., 2002), which are often devoid of soluble iron. The lower iron conditions encountered by C. tepidum may necessitate higher genetic potential for iron acquisition. Interestingly, the openocean cyanobacterium $P$. marinus was not found to encode any genes for transport or synthesis of siderophores. Genes for heme transport or lysis were also not found in this genome. Indeed, $P$. marinus is known for its ability to subsist in low iron regimes, not through increasing its iron income but through lowering its iron expenditures (Partensky et al., 1999; Rusch et al., 2010). Nonetheless, $P$. marinus seems to encode genes involved in the storage (ferritin) and transport $(y f e A B)$ of iron, and these gene were identified by FeGenie.

Using FeGenie, we compared iron gene inventories of two strains of the cyanobacterium Acaryochloris marina, MBIC11017 and CCMEE 5410. Acaryochloris marina are unique in that they use chlorophyll $d$ to capture far-red light during photosynthesis (Swingley et al., 2008), a strategy that may have offered a competitive edge over other cyanobacteria, and led to genome expansion and accumulation of an unusually large number of gene duplicates (Swingley et al., 2008). FeGenie results demonstrate that strain MBIC11017 encodes more genes associated with iron acquisition via siderophore synthesis, iron/siderophore transport, and heme lysis. This is consistent with the isolation of MBIC11017 from a habitat that is more iron-deplete than the one from which CCMEE 5410 was isolated (Miller et al., 2011). Moreover, Miller et al. (2011) have reported a large number of gene duplicates in strain MBIC11017 that are predicted to be involved in iron acquisition. The duplication of genes involved in iron acquisition may be a strategy used for adaptation to a low-iron niche via increased gene dosage (Gallagher and Miller, 2018). The detection of these genomic differences by FeGenie further demonstrates its utility in genomic studies.

Regulators of iron genes were also detected in nearly all analyzed isolate genomes, with the exception of Shewanella oneidensis MR-1 and Aggregatibacter actinomycetemcomitans. Iron gene regulators are often found within operons encoding iron-related genes. For example, the feo operon, in addition to the transporters $f e o A$ and $f e o B$, often encodes the regulator 
feoC. However, in some cases, instead of $f e o C, f e o A B$ are in the same operon as fur (e.g., Geobacter bemidjiensis) or the iron efflux gene feoE (Bennett et al., 2015). Two iron-dependent repressors were also identified adjacent to a gene encoding the iron reduction protein $\mathrm{OmcF}$ in Geobacter bemidjiensis, further suggesting, as in $S$. oneidensis, that dissimilatory iron reduction could be linked to iron uptake. $P$. aeruginosa appears to encode the greatest number of iron gene regulators, such as PchR and Fur, as well as ECF sigma factors FpvI and PvdS, many of which are encoded in close proximity to genes relevant to siderophore synthesis and transport.

FeGenie was also used to analyze the genomes of two intracellular pathogens, which are considered "iron-free" organisms due to an apparent lack of genes associated with iron acquisition, storage, and utilization. FeGenie identified only a few potential iron-related genes. Within the genome of Borrelia burgdorferi, FeGenie identified a fur-family gene that encodes BosR, a zinc-dependent transcriptional regulator (Boylan et al., 2003; Katona et al., 2004), and a ferritin-family gene that encodes $\mathrm{BicA}$, an iron and copper-binding protein that is thought to detoxify cells from iron and copper (Wang P. et al., 2012). BicA is part of a broader Dps (NA-binding protein from starved bacteria) family of proteins. It is thought that bicA expression is regulated by BosR (Boylan et al., 2003). In Treponema pallidum, FeGenie identified three loci corresponding to candidate iron genes. In one locus, $T$. pallidum encodes a Dps-family protein, which may function to accumulate iron. FeGenie also identified two genes potentially involved in the transport of siderophores, hemes, or iron from transferrin/lactoferrin. Indeed, T. pallidum has been reported to bind host lactoferrin and transferrin (Alderete et al., 1988), and may do so using the permease and ATP-binding protein identified by FeGenie (Supplementary Data Sheet S5). Additionally, FeGenie identified a locus with three genes, two of which are predicted to be involved in iron transport and one in gene regulation. The identified gene regulator, related to diphtheria toxin regulatory protein (DtxR), encodes TroR, which is activated by $\mathrm{Mn}^{2+}$ instead of $\mathrm{Fe}^{2+}$ (Posey et al., 1999). Likewise, the identified putative iron transport genes in that operon may be involved in the transport of $\mathrm{Mn}^{2+}$, rather than $\mathrm{Fe}^{2+}$, reflecting a strategy to circumvent iron limitation imposed by the host environment (Posey et al., 1999).

After validating FeGenie against isolate genomes, we utilized FeGenie to examine the iron-related genes and gene neighborhoods in environmental metagenomes, human oral biofilm isolates, and members of the CPR.

\section{Case Study: Iron Redox and Acquisition in Diverse Environmental Metagenomes}

FeGenie was used to analyze 27 metagenomic datasets, representing a broad range of environments, including hydrothermal vent iron mats, a river plume, the open ocean, hot springs, and a serpentinite-hosted ecosystem (see section "Materials and Methods" and Table 2 for site descriptions). Generally, FeGenie's analysis indicate that there are discernable differences in iron maintenance and metabolism strategies based on locale, likely due to differential iron availability and general redox conditions (Figure 5A and Supplementary Data Sheets S6, S7). For example, where iron oxidation and reduction gene counts are high, there appears to be fewer genes for iron acquisition. As expected, the genetic potential for iron acquisition and storage appears to be more important in environments where microorganisms are more likely to encounter iron limitations (Crosa, 1989; Andrews, 1998). This is supported by hierarchical clustering of the iron gene abundances across analyzed metagenomes (Figure 5B), an optional step in FeGenie's pipeline. This offers support for FeGenie's ability to provide meaningful insights into the iron-related genomic potential in environmental metagenomic datasets.

FeGenie demonstrates the potential for iron oxidation and reduction in environments that are rich in reduced iron, including the Rifle Aquifer (Jewell et al., 2016), Jinata Hot Springs (Ward, 2017; Ward et al., 2019), and iron mats found at the Loihi Seamount, Mid-Atlantic Ridge, and Mariana Backarc hydrothermal vent (McAllister et al., 2019). FeGenie also demonstrates the potential for these metabolisms to occur in other environments, including the Amazon river plume (Satinsky et al., 2017) and in the open ocean (Tully et al., 2018) (Figure 5A). While $c y c 2$ appears to be the most widely distributed gene that is associated with iron oxidation, other putative iron oxidases are also identified (e.g., sulfocyanin, $m t o A B$, foxE). Iron reduction is predicted from the occurrence of homologs to $m \operatorname{tr} C A B$, as well as various porin-cytochrome operons homologous to those encoded by Geobacter and Desulfovibrio species. In addition, we identified homologs to the cytochrome OmcS from Geobacter sulfurreducens, thought to be involved in long-distance extracellular electron transfer (Wang et al., 2019), in Loihi iron mats and the open ocean. The presence of significant iron reduction in the open ocean water column is not expected due to generally low iron concentrations. However, as previously suggested by Chiu et al. (2017), niche-specific strategies, such as association with particulate matter or flocs, may take place in the iron-deplete water column and host microbially mediated iron cycling.

While iron oxidation and reduction are predicted in a range of environmental samples analyzed, the greatest number of iron redox genes are predicted in iron-rich ecosystems. Genes associated with dissimilatory iron reduction often coincide with those for iron oxidation. Exceptions to this include the upper centimeters (i.e., syringe samples) of iron mats from Loihi and the Mariana Backarc (McAllister et al., 2019); these samples encode many genes for iron oxidation but have no genes linked exclusively to iron reduction. This may indicate that (1) iron reducers form a non-detectable fraction of the community in those samples, (2) that the geochemical regimes present there do not favor dissimilatory iron reduction, or (3) that there are other, currently unknown, mechanisms for iron reduction occurring. For example, the surficial iron mat sample from the Loihi Seamount appears to have the highest number of genes related to iron oxidation, and none related to iron reduction; it also happens to be the sample dominated by the iron-oxidizing Zetaproteobacteria at 96\% relative abundance (McAllister et al., 2019). Nonetheless, the predicted occurrence of iron reduction in most (7 out of 10) 


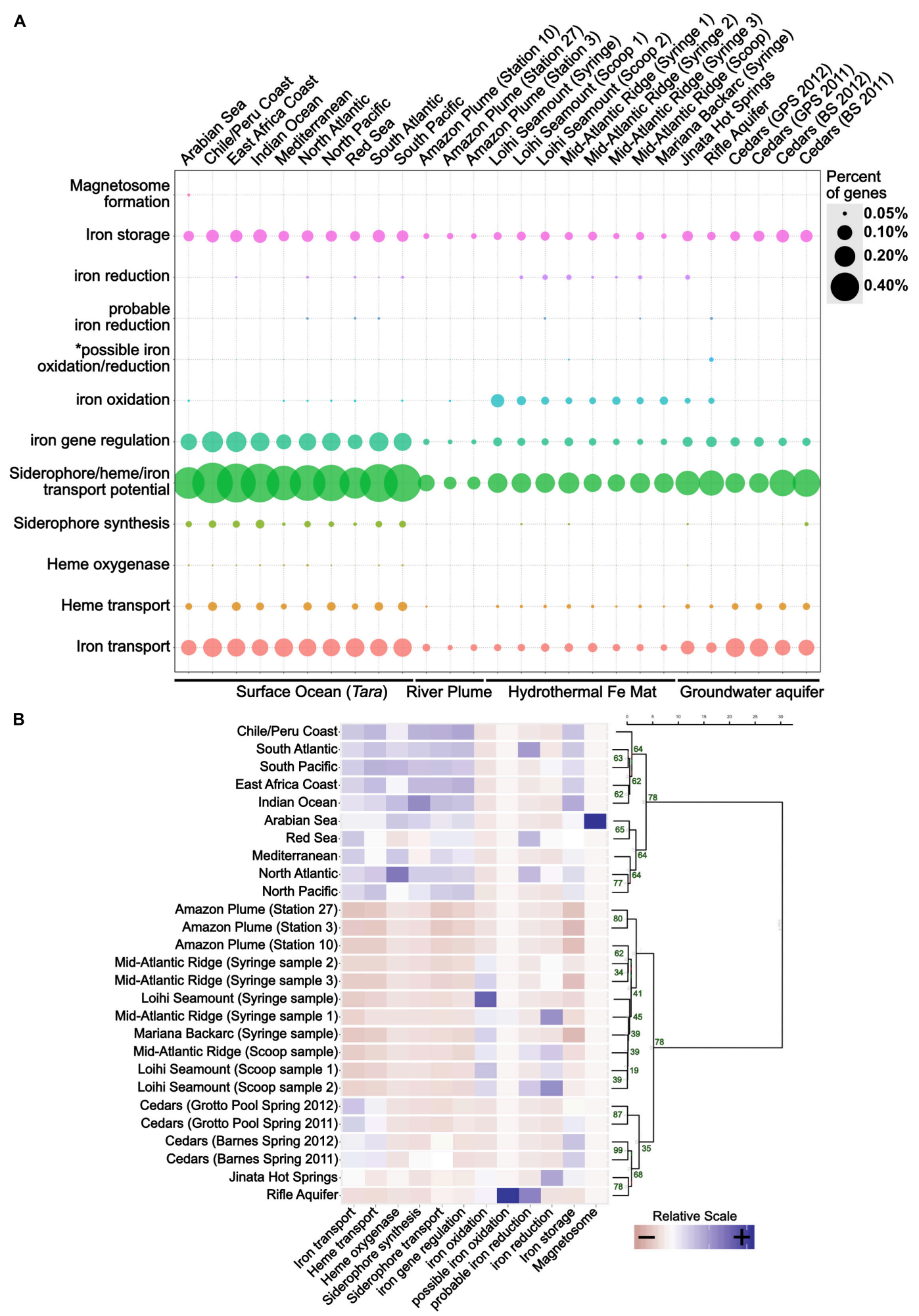

FIGURE 5 | (A) Dot plot showing the distribution of iron genes on 27 metagenomes and (B) a scaled heatmap with accompanying dendrogram that represents hierarchical clustering of metagenome datasets based on identified iron genes. The dot plot shows the relative abundance of iron genes across 27 metagenomes. The size of each dot reflects the number of genes identified for each category, normalized to the number of protein-coding genes predicted within each metagenome. To generate the dendrogram, Ward's method for hierarchical clustering was used, along with the Euclidian distance metric. The heatmap was created from a scaled version of FeGenie's matrix output, which summarizes the amount of iron genes for each category present in each metagenome assembly. GPS, Grotto Pool Spring; BS, Barnes Spring. *This category is reserved for genes related to the mtoAB/pioAB gene family. 
of the iron oxidizer-dominated ecosystems indicates potential interdependence, or even syntrophic interactions, between ironoxidizing and iron-reducing microorganisms (Emerson, 2009).

Metagenomes from the Cedars (Suzuki et al., 2017), a hyperalkaline terrestrial serpentinite-hosted site, encodes a diversity of iron acquisition genes, similar to that observed in the open ocean, suggesting potential iron-limiting conditions. Accordingly, we did not detect any genes associated with iron reduction or oxidation. However, Gibbs energy calculations suggest that iron oxidation and reduction are both feasible metabolisms in serpentinite-hosted systems (Cardace et al., 2015), and electrochemical enrichment of a magnetite-reducer (Rowe et al., 2017) indicates that dissimilatory iron reduction may be occurring within the rare biosphere, biofilms on surfaces of iron-bearing minerals, or iron-containing flocs.

Genes potentially involved in magnetosome formation ( $\mathrm{mam}$ ) are present in only one of the 27 metagenomes analyzed: Arabian Sea surface waters (Tully et al., 2018). The one potential magnetosome-related operon from the Arabian Sea encodes six of the ten mam markers used (mamMOPAQB). FeGenie strictly reports potential homologs to the mam operon genes if the operon is at least $50 \%$ complete. Thus, the general lack of magnetosome formation in the other metagenomes could be a result of FeGenie's strict rules. Alternatively, the microbial communities represented by these metagenomes either (1) do not have magnetotactic microorganisms present at a detectable level or (2) magnetotactic microorganisms present within these communities utilize an unknown strategy for magnetosome formation and/or magnetotaxis.

\section{Case Study: Iron Acquisition by Bacteria Living in the Human Oral Biofilm}

The microbial capability to uptake iron is critical to understanding human oral infections (Wang R.K. et al., 2012). This is because host iron-binding proteins, such as transferrin, lactoferrin, hemoglobin, and ferritin, maintain an environment of low free iron concentrations (estimated $10^{-18} \mathrm{M}$ free iron in living tissues; Weinberg, 1978), inhibiting bacterial growth (Mukherjee, 1985). Here, we used FeGenie to analyze four representative strains from the human oral biofilm community: Aggregatibacter actinomycetemcomitans Y4, Capnocytophaga ochracea DSM 7271, Porphyromonas gingivalis W83, and Streptococcus mutans UA159. Given that these four strains are members of the human oral biofilm (Welch et al., 2016), their iron acquisition systems may be tailored toward the specific strategies needed to survive in the human oral biofilm. Three of these isolates (all except $P$. gingivalis) show generally high numbers of genes involved in iron transport (Figure 4 and Supplementary Data Sheets S4, S5). A. actinomycetemcomitans and $P$. gingivalis have potential genes for heme transport, in line with a previous report of $P$. gingivalis being incapable of synthesizing heme, requiring exogenous iron addition for survival (Roper et al., 2000). A. actinomycetemcomitans, $P$. gingivalis, and Streptococcus mutans also show high genetic potential for siderophore uptake but have no genes implicated in siderophore synthesis.
This suggests that if they do uptake siderophores, they may do so as "cheaters" (bacteria that uptake siderophores produced by other organisms) (Hibbing et al., 2010). In contrast, C. ochracea encodes both siderophore uptake and synthesis genes. No genes associated with dissimilatory iron reduction or oxidation were detected in any of the oral biofilm isolates.

\section{Case Study: Iron-Related Genes Encoded Within the Candidate Phyla Radiation and Other Candidate Taxa}

FeGenie was used to identify the iron-related genes encoded by members of the Candidate Phyla Radiation (CPR) and other candidate taxa. These candidate taxa have been identified by metagenome or single-cell genome assemblies, but the microorganism has yet to be cultivated. Many of the CPR genomes have previously been reconstructed from a metagenome from the Rifle aquifer (Anantharaman et al., 2016) and are largely unexplored with respect to phenotype and role in the environment (Brown et al., 2015). Nonetheless, CPR members are defined by relatively small genomes and very limited metabolic capacity, suggesting that symbiotic lifestyles are likely prevalent among these phyla (Danczak et al., 2017). While we present results for only a select set of 17 candidate taxa (Supplementary Data Sheets S8, S9), all publicly-available genomes from the CPR and other candidate strains were analyzed (Supplementary Data Sheets S10, S11). The 17 selected genomes were chosen to demonstrate differences within these genomes with regard to genomic potential for iron acquisition, storage, and redox-cycling. The candidate strains presented here include members of the candidate phyla OP9 (Caldatribacterium), as well as "Candidatus Rokubacteria," "Candidatus Nealsonbacteria," "Candidatus Zixibacteria," and the novel Archaeal phylum AR4.

Genes for siderophore synthesis were detected in only one of the candidate strains analyzed (Figure 6), while potential for siderophore transport is found in nearly all of the genomes. Gene candidates for heme transport genes, specifically $h m u V$ and hmuY, were found in 4 of the 17 candidate strains analyzed: 'Candidatus Raymondbacteria', 'Candidatus Tectomicrobia,' 'Candidatus Nitrospira defluvii,' and the genome from candidate division KSB1. Out of the 17 candidate strains analyzed, none were found to encode genes associated with heme oxygenases. Interestingly, some CPR genomes, such as "Candidatus Nealsonbacteria," do not seem to encode any genes associated with iron maintenance or metabolism, with the exception of some putative iron transporters. One possible reason for this is that these microorganisms, whose genomes are considerably smaller than typical free-living bacteria, are obligate symbionts (Hug et al., 2016) and may be obtaining iron from their host or using the host's cellular machinery for iron acquisition and utilization. Alternatively, these understudied phyla may be utilizing, thus far, undiscovered mechanisms for iron metabolism, and the genetic underpinnings of these mechanisms may not bear any homology to the HMMs included in FeGenie's database. 


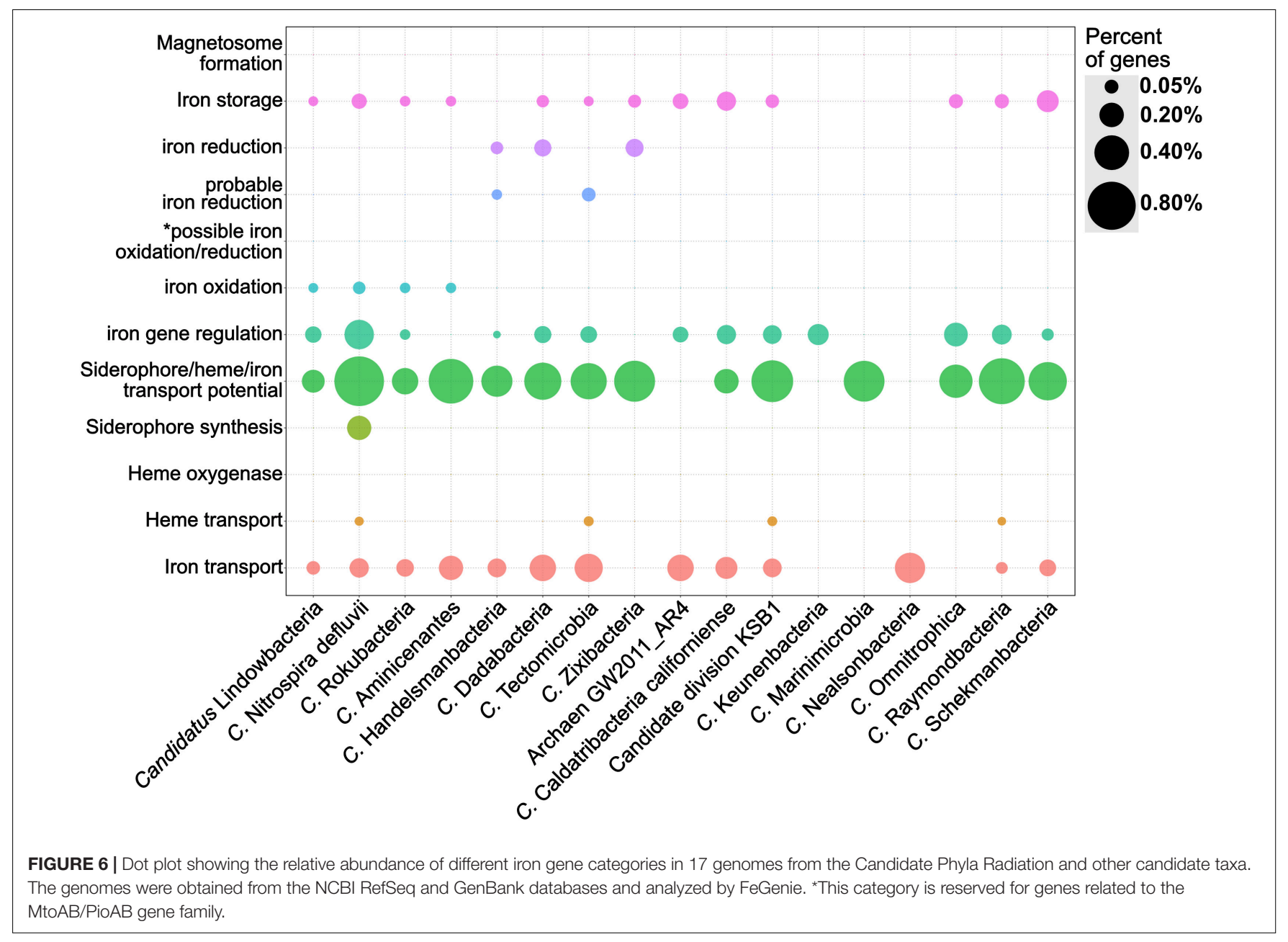

'Candidatus Lindowbacteria,' 'Candidatus Rokubacteria,' 'Candidatus Aminicenantes,' 'Candidatus Handelsmanbacteria', and 'Candidatus Nitrospira defluvii' show genetic potential for iron oxidation via homologs to either cyc2 or sulfocyanin genes. 'Candidatus Nitrospira defluvii, a close relative of the iron-oxidizing Leptospirillum (Lücker et al., 2010) also encodes $a c l A B$ and, thus, may be capable of carbon fixation via the reverse tricarboxylic acid cycle (rTCA). While this metagenome-assembled genome was previously reported as a potential nitrite-oxidizer (Lücker et al., 2010), here we report that it could potentially contribute to primary production using energy generated from iron oxidation. Within the genome of 'Candidatus Tectomicrobia', FeGenie identified homologs to $m \operatorname{tr} A B$. These iron reduction-related genes have not been previously reported in this candidate phylum (Wilson et al., 2014), demonstrating FeGenie's ability to help identify biological processes not previously identified in other reports. 'Candidatus Zixibacteria,' 'Candidatus Tectomicrobia,' 'Candidatus Dadabacteria', and 'Candidatus Handelsmanbacteria' also encode genes implicated in iron reduction via porin-cytochrome operons that share homology with those encoded by iron-reducing Geobacter spp. Taken together, these results suggest a potential role in iron cycling for some of the CPR members and other candidate taxa. Future culture-dependent, physiological work is needed to confirm this potential.

\section{CONCLUSION}

Here, we describe a new HMM database of iron-related genes and a bioinformatics tool, FeGenie, that utilizes this database to analyze genomes and metagenomes. We validated this tool against a select set of 28 isolate genomes and demonstrate that FeGenie accurately detects genes related to iron oxidation/reduction, magnetosome formation, iron regulation, iron transport, siderophore synthesis, and iron storage. Analysis of 27 environmental metagenomes using FeGenie further validated this tool, revealed differences in iron maintenance and potential metabolic strategies across diverse ecosystems, and demonstrates that FeGenie can provide useful insights into the iron gene inventories across habitats. We also used FeGenie to provide insights into the iron metabolisms of 17 of the recently discovered CPR microorganisms and other candidate taxa, and revealed genetic potential not identified in previous reports. 
FeGenie will be continuously updated with new versions as new iron-related genes are discovered.

\section{DATA AVAILABILITY STATEMENT}

The datasets generated for this study can be found in the following GitHub repository: https://github.com/ArkadiyGarber/FeGenie.

\section{AUTHOR CONTRIBUTIONS}

AG, NM, RB, and CC contributed to creating the HMM database. AG programed FeGenie. NM developed the concept. SM collected and processed metagenomic samples from the Loihi Seamount, Mid-Atlantic Ridge, and Mariana Backarc. AG, NM, $\mathrm{AO}, \mathrm{SM}, \mathrm{CC}, \mathrm{RB}$, and $\mathrm{KN}$ wrote the manuscript.

\section{FUNDING}

NM was supported by NASA grant NNA13AA92A and Air Force Office of Scientific Research Grant FA9550-141-0114. AG was supported by NSF EAR grant 1638216 to KN. CC and SM were supported by NSF Geobiology and Low Temperature Geochemistry Grant EAR-1833525, NSF Biological Oceanography Grant OCE-1155290, and ONR grant N00014-17-1-2640. Lawrence Livermore National Laboratory is operated by Lawrence Livermore National Security, LLS, for the U.S. Department of Energy, National Nuclear Security Administration under Contract DE-AC52-07NA27344 (LLNL-JRNL-791160).

\section{ACKNOWLEDGMENTS}

We gratefully thank the following people for their support, advice, and comments: David Emerson, Benjamin Tully, Lewis Ward, Michael Lee, Bonita Lam, Elif Koeksoy, Jeffrey Kimbrel, Shino Suzuki, Catherine Armbruster, Gustavo Ramírez, Thomas Hanson, and Shawn Polson. Dave Emerson provided many useful insights and guidance on development of the iron-related gene database. Ben Tully provided advice and feedback related to the bioinformatics pipeline and HMM development. Lewis Ward generously provided the metagenome assembly for Jinata Hot Springs. Michael Lee, Bonita Lam, Jeffrey Kimbrel, and Elif Koeksoy tested FeGenie and provided comments to improve FeGenie. Shino Suzuki provided comments for the Cedars metagenomes. Catherine

\section{REFERENCES}

Adhikari, P., Berish, S. A., Nowalk, A. J., Veraldi, K. L., Morse, S. A., and Mietzner, T. A. (1996). The $f b p A B C$ locus of Neisseria gonorrhoeae functions in the periplasm-to-cytosol transport of iron. J. Bacteriol. 178, 2145-2149. doi: 10.1128/jb.178.7.2145-2149. 1996
Armbruster provided advice and guidance on iron acquisition pathways and program aesthetics. Gustavo Ramírez aided in the development of R scripts.

\section{SUPPLEMENTARY MATERIAL}

The Supplementary Material for this article can be found online at: https://www.frontiersin.org/articles/10.3389/fmicb. 2020.00037/full\#supplementary-material

FIGURE S1 | Maximum-likelihood phylogenetic tree of six MtrA homologs used to build the MtrA HMM and six "MtoA" homologs used the build the MtoA HMM. This tree represents sequences only from confirmed iron oxidizers and iron reducers. It is important to note that, as far as we currently know, physiological evidence for iron oxidation or reduction capacity only exists for MtrA/MtoA homologs encoded by Rhodopseudomonas palustris TIE-1, Sideroxydans lithotrophicus ES-1, and Shewanella oneidensis MR-1.

TABLE S1 | List of iron-related genes identified by FeGenie.

TABLE S2 | Acquisition of representative genomes. Genome sequences of model microorganisms were downloaded from the NCBI RefSeq database on November 4, 2017 (Pruitt et al., 2007). Additional genome sequences for candidate taxa were obtained using the NCBI accession IDs found in Hug et al. (2016).

TABLE S3 | FeGenie's rules for identifying dissimilatory iron oxidation and reduction. These rules are derived from the genomic co-occurrence, operon structures, and phylogeny of genes previously implicated in these metabolisms.

TABLE S4 | AntiSMASH results of the Bacillus anthracis genome. Cluster 17 and 19 are siderophore operons, where Cluster 17 is the operon that produces petrobactin and Cluster 19 is a siderophore(anthrabactin) with $46 \%$ of genes similar to the bacillibactin gene cluster.

DATA SHEET S1 | Legend for HMM name to genes included in model.

DATA SHEET S2 | FeGenie output for RefSeq representatives in heatmap-formatted table.

DATA SHEET S3 | FeGenie output for RefSeq representatives in long-format summary.

DATA SHEET S4 | FeGenie output for isolate genomes in long-format summary.

DATA SHEET S5 | FeGenie output for isolate genomes in heatmap-formatted table.

DATA SHEET S6 | FeGenie output for metagenomes in long-format summary.

DATA SHEET S7 | FeGenie output for metagenomes in heatmap-formatted table.

DATA SHEET S8 | FeGenie output for CPR and candidate strain genomes in long-format summary.

DATA SHEET S9 | FeGenie output for CPR and candidate strain genomes in heatmap-formatted table.

DATA SHEET S10 | FeGenie output for all CPR and candidate strain genomes in long-format summary.

DATA SHEET S11 | FeGenie output for all CPR and candidate strain genomes in heatmap-formatted table. pallidum for human lactoferrin and transferrin. Genitourin Med. 64, 359-363. doi: 10.1136/sti.64.6.359

Anantharaman, K., Brown, C. T., Hug, L. A., Sharon, I., Castelle, C. J., Probst, A. J., et al. (2016). Thousands of microbial genomes shed light on interconnected biogeochemical processes in an aquifer system. Nat. Commun. 7:13219. doi: $10.1038 /$ ncomms 13219 
Andrews, S. C. (1998). Iron storage in bacteria. Adv. Microbiol. Physiol. 40, 281-351. doi: 10.1016/S0065-2911(08)60134-60134

Andrews, S. C., Robinson, A. K., and Rodriguez-Quiñones, F. (2003). Bacterial iron homeostasis. FEMS Microbiol. Rev. 27, 215-237. doi: 10.1016/S0168-6445(03) 00055-X

Angerer, A., Gaisser, S., and Braun, V. (1990). Nucleotide sequences of the $s f u A$, $s f u B$, and $s f u C$ genes of Serratia marcescens suggest a periplasmic-bindingprotein-dependent iron transport mechanism. J. Bacteriol. 172, 572-578. doi: 10.1128/jb.172.2.572-578.1990

Anzaldi, L. L., and Skaar, E. P. (2010). Overcoming the heme paradox: heme toxicity and tolerance in bacterial pathogens. Infect. Immun. 78, 4977-4989. doi: 10.1128/IAI.00613-610

Arai, W., Taniguchi, T., Goto, S., Moriya, Y., Uehara, H., Takemoto, K., et al. (2018). MAPLE 2.3.0: an improved system for evaluating the functionomes of genomes and metagenomes. Biosci. Biotechnol. Biochem. 82, 1515-1517. doi: $10.1080 / 09168451.2018 .1476122$

Ayala-Castro, C., Saini, A., and Outten, F. W. (2008). Fe-S cluster assembly pathways in bacteria. Microbiol. Mol. Biol. Rev. 72, 110-125. doi: 10.1128/ MMBR.00034-37

Balado, M., Osorio, C. R., and Lemos, M. L. (2008). Biosynthetic and regulatory elements involved in the production of the siderophore vanchrobactin in Vibrio anguillarum. Microbiol 154, 1400-1413. doi: 10.1099/mic.0.2008/ 016618- 16610

Bankevich, A., Nurk, S., Antipov, D., Gurevich, A. A., Dvorkin, M., Kulikov, A. S., et al. (2012). SPAdes: a new genome assembly algorithm and and its application to single-cell sequencing. J. Comput. Biol. 19, 455-477. doi: 10.1089/cmb.2012. 0021

Barco, R. A., Emerson, D., Sylvan, J. B., Orcutt, B. N., Jacobson Meyers, M. E., Ramírez, G. A., et al. (2015). New insight into microbial iron oxidation as revealed by the proteomic profile of an obligate iron-oxidizing chemolithoautotroph. Appl. Environ. Microbiol. 81, 5927-5937. doi: 10.1128/ AEM.01374-15

Barghouthi, S., Payne, S. M., Arceneaux, J. E., and Byers, B. R. (1991). Cloning, mutagenesis, and nucleotide sequence of a siderophore biosynthetic gene (amoA) from Aeromonas hydrophila. J. Bacteriol. 173, 5121-5128. doi: 10.1128/ jb.173.16.5121-5128.1991

Barry, S. M., and Challis, G. L. (2009). Recent advances in siderophore biosynthesis. Curr. Opin. Chem. Biol. 13, 205-215. doi: 10.1016/j.cbpa.2009.03.008

Bathe, S., and Norris, P. R. (2007). Ferrous iron- and sulfur-induced genes in Sulfolobus metallicus. Appl. Environ. Microbiol. 73, 2491-2497. doi: 10.1128/ AEM.02589-2586

Bearden, S. W., Staggs, T. M., and Perry, R. D. (1998). An ABC transporter system of Yersinia pestis allows utilization of chelated iron by Escherichia coli SAB11. J. Bacteriol. 180, 1135-1147. doi: 10.1128/jb.180.5.1135-1147.1998

Bennett, B. D., Brutinel, E. D., and Gralnick, J. A. (2015). A ferrous iron exporter mediates iron resistance in Shewanella oneidensis MR-1. Appl. Environ. Microbiol. 81, 7938-7944. doi: 10.1128/AEM.02835-15

Bolger, A. M., Lohse, M., and Usadel, B. (2014). Trimmomatic: a flexible trimmer for Illumina sequence data. Bioinformatics 30, 2114-2120. doi: 10. 1093/bioinformatics/btu170

Boylan, J. A., Posey, J. E., and Gherardini, F. C. (2003). Borrelia oxidative stress response regulator, BosR: a distinctive $\mathrm{Zn}$-dependent transcriptional activator. Proc. Natl. Acad. Sci. U.S.A 100, 11684-11689. doi: 10.1073/pnas.20329 56100

Braun, M., Killmann, H., Maier, E., Benz, R., and Braun, V. (2002). Diffusion through channel derivatives of the Escherichia coli FhuA transport protein. Eur. J. Biochem. 269, 4948-4959. doi: 10.1046/j.1432-1033.2002.03195.x

Braun, V. (2003). Iron uptake by Escherichia coli. Front. Biosci. 8:s1409-s1421.

Brickman, T. J., and McIntosh, M. A. (1992). Overexpression and purification of ferric enterobactin esterase from Escherichia coli. Demonstration of enzymatic hydrolysis of enterobactin and its iron complex. J. Biol. Chem. 267, 1235012355.

Brillet, K., Ruffenach, F., Adams, H., Journet, L., Gasser, V., Hoegy, F., et al. (2012). An ABC transporter with two periplasmic binding proteins involved in iron acquisition in Pseudomonas aeruginosa. ACS Chem. Biol. 7, 2036-2045. doi: $10.1021 / \mathrm{cb} 300330 \mathrm{v}$
Brooks, B. E., and Buchanan, S. K. (2008). Signaling mechanisms for activation of extracytoplasmic function (ECF) sigma factors. Biochim. Biophys. Acta 1778, 1930-1945. doi: 10.1016/j.bbamem.2007.06.005

Brown, C. T., Hug, L. A., Thomas, B. C., Sharon, I., Castelle, C. J., Singh, A., et al. (2015). Unusual biology across a group comprising more than $15 \%$ of domain Bacteria. Nature 523, 208-211. doi: 10.1038/nature14486

Brown, J. S., and Holden, D. W. (2002). Iron acquisition by Gram-positive bacterial pathogens. Microbes Infect. 4, 1149-1156. doi: 10.1016/S1286-4579(02)016401644

Brune, I., Werner, H., Hüser, A., Kalinowski, J., Pühler, A., and Tauch, A. (2006). The DtxR protein acting as dual transcriptional regulator directs a global regulatory network involved in iron metabolism of Corynebacterium glutamicum. BMC Genomics 7:21. doi: 10.1186/1471-2164-7-21

Cao, J., Woodhall, M. R., Alvarez, J., Cartron, M. L., and Andrews, S. C. (2007). EfeUOB (YcdNOB) is a tripartite, acid-induced and CpxAR-regulated, low-pH $\mathrm{Fe} 2+$ transporter that is cryptic in Escherichia coli $\mathrm{K}-12$ but functional in $E$. coli O157:H7: low pH, Fe2+ transporter in E. coli. Mol. Microbiol. 65, 857-875. doi: $10.1111 / \mathrm{j} .1365-2958.2007 .05802 . \mathrm{x}$

Cardace, D., Meyer-Dombard, D. R., Woycheese, K. M., and Arcilla, C. A. (2015). Feasible metabolisms in high $\mathrm{pH}$ springs of the Philippines. Front. Microbiol. 6:10. doi: 10.3389/fmicb. 2015.00010

Carlson, H. K., Lavarone, A. T., Gorur, A., Yeo, B. S., Tran, R., Melnyk, R. A., et al. (2012). Surface multiheme c-type cytochromes from Thermincola potens and implications for respiratory metal reduction by Gram-positive bacteria. Proc. Natl. Acad. Sci. U.S.A. 109, 1702-1707. doi: 10.1073/pnas.1112905109

Carroll, C. S., and Moore, M. M. (2018). Ironing out siderophore biosynthesis: a review of non-ribosomal peptide synthetase (NRPS)-independent siderophore synthetases. Crit. Rev. Biochem. Mol. Biol. 53, 356-381. doi: 10.1080/10409238. 2018.1476449

Castelle, C., Guiral, M., Malarte, G., Ledgham, F., Leroy, G., Brugna, M., et al. (2008). A new iron-oxidizing/O2-reducing supercomplex spanning both inner and outer membranes, isolated from the extreme acidophile Acidithiobacillus ferrooxidans. J. Biolog. Chem. 283, 25803-25811. doi: 10.1074/jbc.M802496200

Castelle, C. J., Roger, M., Bauzan, M., Brugna, M., Lignon, S., Nimtz, M., et al. (2015). The aerobic respiratory chain of the acidophilic archaeon Ferroplasma acidiphilum: a membrane-bound complex oxidizing ferrous iron. Biochim. Biophys. Acta 1847, 717-728. doi: 10.1016/j.bbabio.2015.04.006

Caza, M., and Kronstad, J. W. (2013). Shared and distinct mechanisms of iron acquisition by bacterial and fungal pathogens of humans. Front. Cell Infect. Microbiol. 3:80. doi: 10.3389/fcimb.2013.00080

Chiu, B. K., Kato, S., McAllister, S. M., Field, E. K., and Chan, C. S. (2017). Novel Pelagic Iron-Oxidizing Zetaproteobacteria from the Chesapeake Bay Oxic-Anoxic Transition Zone. Front. Microbiol. 8:1280. doi: 10.3389/fmicb. 2017.01280

Cianciotto, N. P. (2015). An update on iron acquisition by Legionella pneumophila: new pathways for siderophore uptake and ferric iron reduction. Future Microbiol. 10, 841-851. doi: 10.2217/fmb.15.21

Contreras, H., Chim, N., Credali, A., and Goulding, C. W. (2014). Heme uptake in bacterial pathogens. Curr. Opin. Chem. Biol. 19, 34-41. doi: 10.1016/j.cbpa. 2013.12.014

Cornelis, P., and Dingemans, J. (2013). Pseudomonas aeruginosa adapts its iron uptake strategies in function of the type of infections. Front. Cell Infect. Microbiol. 3:75. doi: 10.3389/fcimb.2013.00075

Coulton, J. W., Mason, P., and Allatt, D. D. (1987), fhuC and $f h u D$ genes for iron(III)-ferrichrome transport into Escherichia coli K-12. J. Bacteriol. 169, 3844-3849. doi: 10.1128/jb.169.8.3844-3849.1987

Croal, L. R., Jiao, Y., and Newman, D. K. (2007). The fox Operon from Rhodobacter strain SW2 Promotes Phototrophic Fe (II) Oxidation in Rhodobacter capsulatus SB1003. J. Bacteriol. 189, 1774-1782. doi: 10.1128/JB.01395-1396

Crosa, J. H. (1989). Genetics and molecular-biology of Siderophore-mediated iron transport in Bacteria. Microbiol. Rev. 53, 517-530. doi: 10.1128/mmbr.53.4. 517-530.1989

Crosa, J. H., and Walsh, C. T. (2002). Genetics and assembly line enzymology of siderophore biosynthesis in bacteria. Microbiol. Mol. Biol. Rev. 66, 223-249. doi: 10.1128/MMBR.66.2.223-249.2002

Danczak, R. E., Johnston, M. D., Kenah, C., Slattery, M., Wrighton, K. C., and Wilkins, M. J. (2017). Members of the candidate phyla radiation are functionally 
differentiated by carbon- and nitrogen-cycling capabilities. Microbiome 5:112. doi: 10.1186/s40168-017-0331-331

Davis, T. L. (2018). Argparse: Command Line Optional and Positional Argument Parser. $R$ package version 2.0.0. Available at: https://cran.r-project.org/web/ packages/argparse/index.html.

de Vries, A., and Ripley, B. D. (2016). Ggdendro: Create Dendrograms and Tree Diagrams Using 'ggplot2'. R package version 0.1-20. Available at: https://CRAN. R-project.org/package=ggdendro (accessed August, 2019).

Deng, X., Dohmae, N., Nealson, K. H., Hashimoto, K., and Okamoto, A. (2018). Multi-heme cytochromes provide a pathway for survival in energy-limited environments. Sci. Adv. 4:eaao5682. doi: 10.1126/sciadv.aao5682

Dixon, S. D., Janes, B. K., Bourgis, A., Carlson, P. E. Jr., and Hanna, P. C. (2012). Multiple $\mathrm{ABC}$ transporters are involved in the acquisition of petrobactin in Bacillus anthracis. Mol. Microbiol. 84, 370-382. doi: 10.1111/j.1365-2958.2012. 08028.x

Duong, T., Park, K., Kim, T., Kang, S. W., Hahn, M. J., Hwang, H. Y., et al. (2014). Structural and functional characterization of an Isd-type haem-degradation enzyme from Listeria monocytogenes. Acta Crystallogr. D Biol. Crystallogr. 70(Pt 3), 615-626. doi: 10.1107/S1399004713030794

Eddy, S. R. (2004). What is a hidden markov model? Nat. Biotechnol. 22, 13151316. doi: $10.1038 /$ nbt1004- 1315

Edgar, R. C. (2004). MUSCLE: multiple sequence alignment with high accuracy and high throughput. Nucleic Acids Res. 32, 1792-1797. doi: 10.1093/nar/gkh340

Ehrlich, H. L., and Newman, D. K. (2008). Geomicrobiology, 5th Edn. Boca Rato, FL: CRC Press.

Eisen, J. A., Nelson, K. E., Paulsen, I. T., Heidelberg, J. F., Wu, M., Dodson, R. J., et al. (2002). The complete genome sequence of Chlorobium tepidum TLS, a photosynthetic, anaerobic, green-sulfur bacterium. Proc. Natl. Acad. Sci. U.S.A. 99, 9509-9514. doi: 10.1073/pnas.132181499

Elliott, A. V. C., Plach, J. M., Droppo, I. G., and Warren, L. A. (2014). Collaborative microbial Fe-redox cycling by pelagic floc bacteria across wide ranging oxygenated aquatic systems. Chem. Geol. 366, 90-102. doi: 10.1016/j. chemgeo.2013.11.017

Emerson, D. (2009). Potential for Iron-reduction and Iron-cycling in Iron. Geomicrobiol. J. 26, 639-647. doi: 10.1080/01490450903269985

Emerson, D. (2016). The irony of iron - biogenic iron oxides as an iron source to the ocean. Front. Microbiol. 6:1502. doi: 10.3389/fmicb.2015.01502

Emerson, D., Field, E. K., Chertkov, O., Davenport, K. W., Goodwin, L., Munk, C., et al. (2013). Comparative genomics of freshwater Fe-oxidizing bacteria: implications for physiology, ecology, and systematics. Front. Microbiol. 4:254. doi: $10.3389 /$ fmicb.2013.00254

Emerson, D., and Moyer, C. L. (2002). Neutrophilic Fe-oxidizing bacteria are abundant at the Loihi Seamount hydrothermal vents and play a major role in $\mathrm{Fe}$ oxide deposition. Appl. Environ. Microbiol. 68, 3085-3093. doi: 10.1128/AEM. 68.6.3085-3093.2002

Emerson, D., Rentz, J. A., Lilburn, T. G., Davis, R. E., Aldrich, H., Chan, C., et al. (2007). A Novel Lineage of Proteobacteria involved in formation of marine feoxidizing microbial mat communities. PLoS One. 2:e667. doi: 10.1371/journal. pone.0000667

Escolar, L., Pérez-Martín, J., and de Lorenzo, V. (1998). Binding of the fur (ferric uptake regulator) repressor of Escherichia coli to arrays of the GATAAT sequence. J. Mol. Biol. 283, 537-547. doi: 10.1006/jmbi.1998.2119

Faraldo-Gómez, J. D., and Sansom, M. S. P. (2003). Acquisition of siderophores in Gram-negative bacteria. Nat. Rev. Mol. Cell Biol. 4, 105-116. doi: 10.1038/ nrm1015

Fillat, M. F. (2014). The fur (ferric uptake regulator) superfamily: DIVERSITY and versatility of key transcriptional regulators. Arch. Biochem. Biophys. 546, 41-52. doi: 10.1016/j.abb.2014.01.029

Finn, R. D., Coggill, P., Eberhardt, R. Y., Eddy, S. R., Mistry, J., Mitchell, A. L., et al. (2016). The Pfam protein families database: towards a more sustainable future. Nucleic Acids Res. 44, D279-D285. doi: 10.1093/nar/gkv1344

Finneran, K. T., Johnsen, C. V., and Lovley, D. R. (2003). Rhodoferax ferrireducens sp. nov., a psychrotolerant, facultatively anaerobic bacterium that oxidizes acetate with the reduction of Fe (II). Int. J. Syst. Evol. Microbiol. 53(Pt 3), 669-673. doi: 10.1099/ijs.0.02298-2290

Friedman, J., Lad, L., Deshmukh, R., Li, H., Wilks, A., and Poulos, T. L. (2003). Crystal structures of the NO- and CO-bound heme oxygenase from Neisseriae meningitidis. Implications for O2 activation. J. Biol. Chem. 278, 34654-34659. doi: 10.1074/jbc.M302985200

Friedman, J., Lad, L., Li, H., Wilks, A., and Poulos, T. L. (2004). Structural basis for novel delta-regioselective heme oxygenation in the opportunistic pathogen Pseudomonas aeruginosa. Biochem 43, 5239-5245. doi: 10.1021/bi049687g

Fullerton, H., Hager, K. W., McAllister, S. M., and Moyer, C. L. (2017). Hidden diversity revealed by genome-resolved metagenomics of iron-oxidizing microbial mats from Lo'ihi Seamount. Hawai'i. ISME J. 11, 1900-1914. doi: 10.1038/ismej.2017.40

Gallagher, A. L., and Miller, S. R. (2018). GBE Expression of novel gene content drives adaptation to low iron in the cyanobacterium acaryochloris. Genome Biol. Evol. 10, 1484-1492. doi: 10.1093/gbe/evy099

Ganne, G., Brillet, K., Basta, B., Roche, B., Hoegy, F., Gasser, V., et al. (2017). Iron Release from the siderophore pyoverdine in Pseudomonas aeruginosa involves three new actors: FpvC. FpvG, and FpvH. ACS Chem. Biol. 12, 1056-1065. doi: 10.1021/acschembio.6b01077

Gao, H., Obraztova, A., Stewart, N., Popa, R., Fredrickson, J. K., Tiedje, J. M., et al. (2006). Shewanella loihica sp. nov., isolated from iron-rich microbial mats in the Pacific Ocean. Int. J. Syst. Evol. Microbiol. 56, 1911-1916. doi: 10.1099/ijs.0. 64354-64350

Garber, A. I. (2018). The Role of a Porin-Cytochrome Fusion in Neutrophilic Fe Oxidation: Insights From Functional Characterization and Metatranscriptomics. Theses M.Sc.University of Delaware, Newark, DE.

Garcia-Herrero, A., Peacock, R. S., Howard, S. P., and Vogel, H. J. (2007). The solution structure of the periplasmic domain of the TonB system ExbD protein reveals an unexpected structural homology with siderophorebinding proteins. Mol. Microbiol. 66, 872-889. doi: 10.1111/j.1365-2958.2007. 05957.x

Golyshina, O. V., Pivovarova, T. A., Karavaiko, G. I., Kondrat, T. F., Moore, E. R. B., Abraham, W., et al. (2000). Ferroplasma acidiphilum gen. nov., sp. nov., an cellwall-lacking, mesophilic member of the Ferroplasmaceae fam. nov., comprising a distinct lineage of the Archaea. Int. J. Syst. Evol. Microbiol. 50(Pt 3), 997-1006. doi: 10.1099/00207713-50-3-997

Gong, S., Bearden, S. W., Geoffroy, V. A., Fetherston, J. D., and Perry, R. D. (2001). Characterization of the Yersinia pestis $\mathrm{Yfu} \mathrm{ABC}$ inorganic iron transport system. Infect. Immun. 69, 2829-2837. doi: 10.1128/IAI.67.5.2829-2837.2001

Grant, R. A., Filman, D. J., Finkel, S. E., Kolter, R., and Hogle, J. M. (1998). The crystal structure of Dps, a ferritin homolog that binds and protects DNA. Nat. Struct. Biol. 5, 294-303. doi: 10.1038/nsb0498-294

Graves, A. B., Morse, R. P., Chao, A., Iniguez, A., Goulding, C. W., and Liptak, M. D. (2014). Crystallographic and spectroscopic insights into heme degradation by Mycobacterium tuberculosis MhuD. Inorg. Chem. 53, 59315940. doi: 10.1021/ic500033b

Gray-Owen, S. D., Loosmore, S., and Schryvers, A. B. (1995). Identification and characterization of genes encoding the human transferrin-binding proteins from Haemophilus influenzae. Infect. Immun. 63, 1201-1210. doi: 10.1128/iai. 63.4.1201-1210.1995

Grossman, M. J., Hinton, S. M., Minak-Bernero, V., Slaughter, C., and Stiefel, E. I. (1992). Unification of the ferritin family of proteins. Proc. Natl. Acad. Sci. U.S.A. 89, 2419-2423. doi: 10.1073/pnas.89.6.2419

Guedon, E., and Helmann, J. D. (2003). Origins of metal ion selectivity in the DtxR/MntR family of metalloregulators. Mol. Microbiol. 48, 495-506. doi: 10.1046/j.1365-2958.2003.03445.x

Gulick, A. M. (2017). Nonribosomal peptide synthetase biosynthetic clusters of ESKAPE pathogens. Nat. Prod. Rep. 34, 981-1009. doi: 10.1039/C7NP00029D

Gupta, D., Sutherland, M. C., Rengasamy, K., Meacham, J. M., Kranz, R. G., and Bose, A. (2019). Photoferrotrophs Produce a PioAB electron conduit for extracellular electron uptake. mBio 10, e2668-e2619. doi: 10.1128/mBio.026682619

Hantke, K., Nicholson, G., Rabsch, W., and Winkelmann, G. (2003). Salmochelins, siderophores of Salmonella enterica and uropathogenic Escherichia coli strains, are recognized by the outer membrane receptor IroN. Proc. Natl. Acad. Sci. U.S.A. 100, 3677-3682. doi: 10.1073/pnas.0737682100

He, S., Barco, R. A., Emerson, D., and Roden, E. E. (2017). Comparative genomic analysis of neutrophilic Iron (II) oxidizer genomes for candidate genes in extracellular electron transfer. Front. Microbiol. 8:1584. doi: 10.3389/fmicb. 2017.01584 
Hedrich, S., Schlömann, M., and Barrie Johnson, D. (2011). The iron-oxidizing proteobacteria. Microbiology 157, 1551-1564. doi: 10.1099/mic.0.045344-45340

Heinrichs, D. E., and Poole, K. (1996). PchR, a regulator of ferripyochelin receptor gene (fptA) expression in Pseudomonas aeruginosa, functions both as an activator and as a repressor. J. Bacteriol. 178, 2586-2592. doi: 10.1128/jb.178. 9.2586-2592.1996

Hibbing, M. E., Fuqua, C., Parsek, M. R., and Peterson, S. B. (2010). Bacterial competition: surviving and thriving in the microbial jungle. Nat. Rev. Microbiol. 8, 15-25. doi: 10.1038/nrmicro2259

Honsa, E. S., Maresso, A. W., and Highlander, S. K. (2014). Molecular and evolutionary analysis of NEAr-iron transporter (NEAT) domains. PLoS One 9:e104794. doi: 10.1371/journal.pone.0104794

Hu, Y., Jiang, F., Guo, Y., Shen, X., Zhang, Y., Zhang, R., et al. (2011). Crystal structure of HugZ, a novel heme oxygenase from Helicobacter pylori. J. Biol. Chem. 286, 1537-1544. doi: 10.1074/jbc.M110.172007

Hug, L. A., Baker, B. J., Anantharaman, K., Brown, C. T., Probst, A. J., Castelle, C. J., et al. (2016). A new view of the tree of life. Nat. Microbiol. 1, 1-6. doi: 10.1038/nmicrobiol.2016.48

Hyatt, D., Chen, G. L., LoCascio, P. F., Land, M. L., Larimer, F. W., and Hauser, L. J. (2010). Prodigal: prokaryotic gene recognition and translation initiation site identification. BMC Bioinformatics 11:119. doi: 10.1186/1471-2105-11-119

Ilbert, M., and Bonnefoy, V. (2013). Insight into the evolution of the iron oxidation pathways. Biochim. Biophys. Acta 1827, 161-175. doi: 10.1016/j.bbabio.2012.10.001

Jeans, C., Singer, S. W., Chan, C. S., VerBerkmoes, N. C., Shah, M., Hettich, R. L., et al. (2008). Cytochrome 572 is a conspicuous membrane protein with iron oxidation activity purified directly from a natural acidophilic microbial community. ISME J. 2, 542-550. doi: 10.1038/ismej.2008.17

Jewell, T. N. M., Karaoz, U., Brodie, E. L., Williams, K. H., and Beller, H. R. (2016). Metatranscriptomic evidence of pervasive and diverse chemolithoautotrophy relevant to $\mathrm{C}, \mathrm{S}, \mathrm{N}$ and $\mathrm{Fe}$ cycling in a shallow alluvial aquifer. ISME J. 10, 2106-2117. doi: 10.1038/ismej.2016.25

Jiao, Y., Kappler, A., Croal, L. R., and Newman, D. K. (2005). Isolation and Characterization of a Genetically Tractable Photoautotrophic Fe(II)-Oxidizing Bacterium, Rhodopseudomonas palustris Strain TIE-1. Appl. Environ. Microbiol. 71, 4487-4496. doi: 10.1128/AEM.71.8.4487

Jiao, Y., and Newman, D. K. (2007). The pio operon is essential for phototrophic $\mathrm{Fe}(\mathrm{II})$ oxidation in Rhodopseudomonas palustris TIE-1. J. Bacteriol. 189, 17651773. doi: 10.1128/JB.00776-776

Johnson, L. S., Eddy, S. R., and Portugaly, E. (2010). Hidden Markov model speed heuristic and iterative HMM search procedure. BMC Bioinformatics 11:431. doi: 10.1186/1471-2105-11-431

Kadi, N., and Challis, G. L. (2009). "Chapter 17 Siderophore Biosynthesis," in Methods in Enzymology. Amsterdam: Elsevier, 431-457.

Kanehisa, M., Sato, Y., and Morishima, K. (2016). BlastKOALA and GhostKOALA: KEGG Tools for functional characterization of genome and metagenome sequences. J. Mol. Biol. 428, 726-731. doi: 10.1016/j.jmb.2015.11.006

Kassambara, A. (2017). Ggpubr: 'ggplot2' Based Publication Ready Plots. $R$ package version 0.1.6. Available at: https://CRAN.R-project.org/package= ggpubr (accessed August, 2019).

Katoh, H., Hagino, N., Grossman, A. R., and Ogawa, T. (2001). Genes essential to iron transport in the Cyanobacterium Synechocystis sp. strain PCC 6803. J. Bacteriol. 183, 2779-2784. doi: 10.1128/JB.183.9.2779-2784.2001

Katona, L. I., Tokarz, R., Kuhlow, C. J., Benach, J., and Benach, J. L. (2004). The Fur Homologue in Borrelia burgdorferi †. J. Bacteriol. 186, 6443-6456. doi: 10.1128/JB.186.19.6443

Keating, T. A., Marshall, C. G., and Walsh, C. T. (2000). Reconstitution and characterization of the Vibrio cholerae vibriobactin synthetase from VibB, VibE, VibF, and VibH. Biochemistry 39, 15522-15530. doi: 10.1021/bi0016523

Kolinko, S., Richter, M., Glockner, F. O., Brachmann, A., and Schuler, D. (2016). Single-cell genomics of uncultivated deep-branching magnetotactic bacteria reveals a conserved set of magnetosome genes. Environ. Microbiol. 18, 21-37. doi: 10.1111/1462-2920.12907

Koropatkin, N., Randich, A. M., Bhattacharyya-Pakrasi, M., Pakrasi, H. B., and Smith, T. J. (2007). The structure of the iron-binding protein, FutA1, from Synechocystis 6803. J. Biol. Chem. 282, 27468-27477. doi: 10.1074/jbc. M704136200
Köster, W., and Braun, V. (1989). Iron-hydroxamate transport into Escherichia coli K12: localization of FhuD in the periplasm and of FhuB in the cytoplasmic membrane. Mol. Gen. Genet. 217, 233-239. doi: 10.1007/bf0246 4886

Kranzler, C., Lis, H., Finkel, O. M., Schmetterer, G., Shaked, Y., and Keren, N. (2014). Coordinated transporter activity shapes high-affinity iron acquisition in cyanobacteria. ISME J. 8, 409-417. doi: 10.1038/ismej.2013.161

Krewulak, K. D., and Vogel, H. J. (2011). TonB or not TonB: is that the question? Biochem. Cell Biol. 89, 87-97. doi: 10.1139/O10-141

Lamont, I. L., and Martin, L. W. (2003). Identification and characterization of novel pyoverdine synthesis genes in Pseudomonas aeruginosa. Microbiology 149(Pt 4), 833-842. doi: 10.1099/mic.0.26085-26080

Lau, C. K., Krewulak, K. D., and Vogel, H. J. (2016). Bacterial ferrous iron transport: the Feo system. FEMS Microbiol. Rev. 40, 273-298. doi: 10.1093/femsre/fuv049

Lemos, M. L., Balado, M., and Osorio, C. R. (2010). Anguibactin- versus vanchrobactin-mediated iron uptake in Vibrio anguillarum: evolution and ecology of a fish pathogen. Environ. Microbiol. Rep. 2, 19-26. doi: 10.1111/j. 1758-2229.2009.00103.x

Light, S. H., Su, L., Rivera-Lugo, R., Cornejo, J. A., Louie, A., Iavarone, A. T., et al. (2018). A flavin-based extracellular electron transfer mechanism in diverse Gram-positive bacteria. Nature 562, 140-144. doi: 10.1038/s41586-018-0498-Z

Liu, J., Wang, Z., Belchik, S. M., Edwards, M. J., Liu, C., Kennedy, D. W., et al. (2012). Identification and characterization of MtoA: a decaheme c-type cytochrome of the neutrophilic Fe(ll)-oxidizing bacterium Sideroxydans lithotrophicus ES-1. Front. Microbiol. 3:37. doi: 10.3389/fmicb.2012.00037

Liu, X., Gong, J., Wei, T., Wang, Z., Du, Q., Zhu, D., et al. (2012). Crystal structure of HutZ, a heme storage protein from Vibrio cholerae: a structural mismatch observed in the region of high sequence conservation. BMC Struc. Biol. 12:23. doi: $10.1186 / 1472-6807-12-23$

Lovley, D. R., and Phillips, E. J. (1988). Novel mode of microbial energy metabolism: organic carbon oxidation coupled to dissimilatory reduction of iron or manganese. Appl. Environ. Microbiol. 54, 1472-1480. doi: 10.1128/aem. 54.6.1472-1480.1988

Lower, B. H., Shi, L., Yongsunthon, R., Droubay, T. C., McCready, D. E., and Lower, S. K. (2007). Specific bonds between an iron oxide surface and outer membrane cytochromes MtrC and OmcA from Shewanella oneidensis MR-1. J. Bacteriol. 189, 4944-4952. doi: 10.1128/Jb.01518-1516

Lücker, S., Wagner, M., Maixner, F., Pelletier, E., Koch, H., and Vacherie, B. (2010). A Nitrospira metagenome illuminates the physiology and evolution of globally important nitrite-oxidizing bacteria. Proc. Natl. Acad. Sci. U.S.A. 107, 13479-13484. doi: 10.1073/pnas.1003860107

Luscher, A., Moynié, L., Auguste, P. S., Bumann, D., Mazza, L., Pletzer, D., et al. (2018). TonB-Dependent receptor repertoire of Pseudomonas aeruginosa for uptake of siderophore-drug conjugates. Antimicrob. Agents Chemother. 62:e00097-18.. doi: 10.1128/AAC.00097-18

Lynch, D., O’Brien, J., Welch, T., Clarke, P., Cuiv, P. O., Crosa, J. H., et al. (2001). Genetic organization of the region encoding regulation, biosynthesis, and transport of rhizobactin 1021, a siderophore produced by Sinorhizobium meliloti. J. Bacteriol. 183, 2576-2585. doi: 10.1128/JB.183.8.2576-2585.2001

Madden, T. (2013). "The BLAST sequence analysis tool," in: The NCBI Handbook, 2nd Edn. eds J. Beck, D. Benson, J. Coleman, M. Hoeppner, M. Johnson, D. Maglott, et al. (Bethesda, MD: National Center for Biotechnology Information).

Mahé, B., Masclaux, C., Rauscher, L., Enard, C., and Expert, D. (1995). Differential expression of two siderophore-dependent iron-acquisition pathways in Erwinia chrysanthemi 3937: characterization of a novel ferrisiderophore permease of the ABC transporter family. Mol. Microbiol. 18, 33-43. doi: 10.1111/j.1365-2958. 1995.mmi_18010033.x

Martínez, J. L., Herrero, M., and de Lorenzo, V. (1994). The organization of intercistronic regions of the aerobactin operon of pColV-K30 may account for the differential expression of the iucABCD iutA genes. J. Mol. Biol. 238, 288-293. doi: 10.1006/jmbi.1994.1290

Matsui, T., Furukawa, M., Unno, M., Tomita, T., and Ikeda-Saito, M. (2005). Roles of distal Asp in heme oxygenase from Corynebacterium diptheriae, $\mathrm{HmuO}$ : a water-driven oxygen activation mechanism. J. Biol. Chem. 280, 2981-2989. doi: 10.1074/jbc.M410263200

Matsunaga, T., Okamura, Y., Fukuda, Y., and Wahyudi, A. T. (2005). Complete genome sequence of the facultative anaerobic magnetotactic bacterium 
Magnetospirillum sp. strain AMB-1. DNA Res. 12, 157-166. doi: 10.1093/ dnares/dsi002

May, J. J., Wendrich, T. M., and Marahiel, M. A. (2001). The dhb operon of Bacillus subtilis encodes the biosynthetic template for the catecholic siderophore 2,3dihydroxybenzoate-glycine-threonine trimeric ester bacillibactin. J. Biol. Chem. 276, 7209-7217. doi: 10.1074/jbc.M009140200

McAllister, S. M., Polson, S. W., Butterfield, D. A., Glazer, B. T., Sylvan, J. B., and Chan, C. S. (2019). Validating the Cyc2 neutrophilic Fe oxidation pathway using meta-omics of Zetaproteobacteria iron mats at marine hydrothermal vents. bioRxiv [pre print]. doi: 10.1101/722066

Miethke, M., Klotz, O., Linne, U., May, J. J., Beckering, C. L., and Marahiel, M. A. (2006). Ferri-bacillibactin uptake and hydrolysis in Bacillus subtilis. Mol. Microbiol. 61, 1413-1427. doi: 10.1111/j.1365-2958.2006.05321.x

Miethke, M., Monteferrante, C. G., Marahiel, M. A., and van Dijl, J. M. (2013). The Bacillus subtilis EfeUOB transporter is essential for high-affinity acquisition of ferrous and ferric iron. Biochim. Biophys. Acta 1833, 2267-2278. doi: 10.1016/j. bbamcr.2013.05.027

Miller, S. R., Wood, A. M., Blankenship, R. E., Kim, M., and Ferriera, S. (2011). Dynamics of gene duplication in the genomes of chlorophyll d -producing cyanobacteria: implications for the ecological niche. Genome Biol. Evol. 3, 601-613. doi: 10.1093/gbe/evr060

Morgan, J. W., and Anders, E. (1980). Chemical composition of earth, venus, and mercury. Proc. Natl. Acad. Sci. U.S.A. 77, 6973-6977. doi: 10.1073/pnas.77.12. 6973

Morrissey, J. A., Cockayne, A., Hill, P. J., and Williams, P. (2000). Molecular cloning and analysis of a putative siderophore $\mathrm{ABC}$ transporter from Staphylococcus aureus. Infect. Immun. 68, 6281-6288. doi: 10.1128/iai.68.11. 6281-6288.2000

Morton, D. J., Seale, T. W., Madore, L. L., VanWagoner, T. M., Whitby, P. W., and Stull, T. L. (2007). The haem-haemopexin utilization gene cluster (hxuCBA) as a virulence factor of Haemophilus influenzae. Microbiol 153(Pt 1), 215-224. doi: 10.1099/mic.0.2006/000190-190

Moynie, L., Luscher, A., Rolo, D., Pletzer, D., Tortajada, A., Weingart, H., et al. (2017). Structure and Function of the PiuA and PirA SiderophoreDrug Receptors from Pseudomonas aeruginosa and Acinetobacter baumannii. Antimicrob. Agents Chemother. 61:e02531-16. doi: 10.1128/AAC.025312516

Mukherjee, S. (1985). The role of crevicular fluid iron in periodontal disease. J. Periodontol. 56(Suppl. 11S), 22-27. doi: 10.1902/jop.1985.56. $11 \mathrm{~s} .22$

Nealson, K. H., and Saffarini, D. (1994). Iron and manganese in anaerobic respiration: environmental significance, physiology, and regulation. Ann .Rev. Microbiol. 48, 311-343. doi: 10.1146/annurev.mi.48.100194.001523

Nurk, S., Meleshko, D., Korobeynikov, A., and Pevzner, P. A. (2017). metaSPAdes: a new versatile metagenomic assembler. Genome Res. 27, 824-834. doi: 10.1101/ gr.213959.116.4

Ochsner, U. A., Johnson, Z., and Vasil, M. L. (2000). Genetics and regulation of two distinct haem-uptake systems, phu and has, in Pseudomonas aeruginosa. Microbiology 146(Pt 1), 185-198. doi: 10.1099/00221287-146$1-185$

Ollinger, J., Song, K. B., Antelmann, H., Hecker, M., and Helmann, J. D. (2006). Role of the Fur regulon in iron transport in Bacillus subtilis. J. Bacteriol. 188, 3664-3673. doi: 10.1128/JB.188.10.3664-3673.2006

Overbeek, R., Olson, R., Pusch, G. D., Olsen, G. J., Davis, J. J., Disz, T., et al. (2014). The SEED and the rapid annotation of microbial genomes using subsystems technology (RAST). Nucleic Acids Res. 42, D206-D214. doi: 10. 1093/nar/gkt1226

Oves-Costales, D., Kadi, N., Fogg, M. J., Song, L., Wilson, K. S., and Challis, G. L. (2007). Enzymatic logic of anthrax stealth siderophore biosynthesis: AsbA catalyzes ATP-dependent condensation of citric acid and spermidine. J. Am. Chem. Soc. 129, 8416-8417. doi: 10.1021/ja072391o

Pandey, A., Bringel, F., and Meyer, J. (1994). Iron requirement and search for siderophores in lactic acid bacteria. Appl. Microbiol. Biotechnol. 40, 735-739. doi: 10.1007/BF00173337

Park, S., Choi, S., and Choe, J. (2012). Bacillus subtilis HmoB is a heme oxygenase with a novel structure. BMB Rep. 45, 239-241. doi: 10.5483/bmbrep.2012. 45.4.239
Partensky, F., Hess, W. R., and Vaulot, D. (1999). Prochlorococcus, a marine photosynthetic prokaryote of global significance. Micorbiol. Mol. Biol. Rev. 63, $106-127$.

Peuckert, F., Ramos-Vega, A. L., Miethke, M., Schwörer, C. J., Albrecht, A. G., Oberthür, M., et al. (2011). The siderophore binding protein FeuA shows limited promiscuity toward exogenous triscatecholates. Chem. Biol. 18, 907919. doi: 10.1016/j.chembiol.2011.05.006

Pitts, K. E., Dobbin, P. S., Reyes-Ramirez, F., Thomson, A. J., Richardson, D. J., and Seward, H. E. (2003). Characterization of the Shewanella oneidensis MR-1 decaheme cytochrome MtrA: expression in Escherichia coli confers the ability to reduce soluble Fe(III) chelates. J. Biol. Chem. 278, 27758-27765. doi: 10.1074/ jbc.M302582200

Posey, J. E., and Gherardini, F. C. (2000). Lack of a Role for Iron in the Lyme Disease Pathogen. Science 288, 1651-1654.

Posey, J. E., Hardham, J. M., Norris, S. J., and Gherardini, F. C. (1999). Characterization of a manganese-dependent regulatory protein, TroR, from Treponema pallidum. Proc. Natl. Acad. Sci. U.S.A. 96, 10887-10892. doi: 10. 1073/pnas.96.19.10887

Pruitt, K. D., Tatusova, T., and Maglott, D. R. (2007). NCBI reference sequences (RefSeq): a curated non-redundant sequence database of genomes, transcripts and proteins. Nucleic Acids Res. 35, D61-D65. doi: 10.1093/nar/gkl842

Quaiser, A., Bodi, X., Dufresne, A., Naquin, D., Francez, A. J., Dheilly, A., et al. (2014). Unraveling the stratification of an iron-oxidizing microbial mat by metatranscriptomics. PLoS One 9:e102561. doi: 10.1371/journal.pone.0102561

Quevillon, E., Silventoinen, V., Pillai, S., Harte, N., Mulder, N., Apweiler, R., et al. (2005). InterProScan: protein domains identifier. Nucleic Acids Res. 33, W116-W120. doi: 10.1093/nar/gki442

R.Core Team, (2013). R: A Language and Environment for Statistical Computing. Vienna: R Core Team.

Reinhart, A., and Oglesby-Sherrouse, A. (2016). Regulation of Pseudomonas aeruginosa Virulence by Distinct Iron Sources. Genes 7:126. doi: 10.3390/ genes7120126

Reniere, M. L., Ukpabi, G. N., Harry, S. R., Stec, D. F., Krull, R., Wright, D. W., et al. (2010). The IsdG-family of heme oxygenases degrades heme to a novel chromophore. Mo.l Microbiol. 75, 1529-1538. doi: 10.1111/j.1365-2958.2010. 07076.x

Richardson, D. J., Butt, J. N., Fredrickson, J. K., Zachara, J. M., Shi, L., Edwards, M. J., et al. (2012). The 'porin-cytochrome' model for microbe-to-mineral electron transfer. Mol. Microbiol. 85, 201-212. doi: 10.1111/j.1365-2958.2012. 08088.x

Rivera, M. (2017). Bacterioferritin: structure, dynamics, and protein-protein interactions at play in iron storage and mobilization. Acc. Chem. Res. 50, 331-340. doi: 10.1021/acs.accounts.6b00514

Rodriguez, G. M., Voskuil, M. I., Gold, B., Schoolnik, G. K., and Smith, I. (2002). ideR, an essential gene in Mycobacterium tuberculosis: role of IdeR in irondependent gene expression, iron metabolism, and oxidative stress response. Infect. Immun. 70, 3371-3381. doi: 10.1128/IAI.70.7.3371-3381.2002

Roper, J. M., Raux, E., Brindley, A. A., Schubert, H. L., Gharbia, S. E., Shah, H. N., et al. (2000). The enigma of cobalamin (Vitamin $\mathrm{B}_{12}$ ) biosynthesis in Porphyromonas gingivalis. J. Biol. Chem. 275, 40316-40323. doi: 10.1074/jbc. M007146200

Rost, B. (1999). Twilight zone of protein sequence alignments. Protein Eng. Des. Sel. 12, 85-94. doi: 10.1093/protein/12.2.85

Rowe, A. R., Yoshimura, M., Larowe, D. E., Bird, L. J., Amend, J. P., Hashimoto, K., et al. (2017). In situ electrochemical enrichment and isolation of a magnetitereducing bacterium from a high $\mathrm{pH}$ serpentinizing spring. Environ. Microbiol. 19, 2272-2285. doi: 10.1111/1462-2920.13723

Rusch, D. B., Martiny, A. C., Dupont, C. L., Halpern, A. L., and Venter, J. C. (2010). Characterization of Prochlorococcus clades from iron-depleted oceanic regions. Proc. Natl. Acad. Sci. U.S.A. 107, 16184-16189. doi: 10.1073/pnas.1009513107

Sachla, A. J., Ouattara, M., Romero, E., Agniswamy, J., Weber, I. T., Gadda, G., et al. (2016). In vitro heme biotransformation by the HupZ enzyme from Group A Streptococcus. Biometals 29, 593-609. doi: 10.1007/s10534-016-9937-1

Santos, T. C., Silva, M. A., Morgado, L., Dantas, J. M., and Salgueiro, C. A. (2015). Diving into the redox properties of Geobacter sulfurreducens cytochromes: a model for extracellular electron transfer. Dalton. Trans. 44, 9335-9344. doi: 10.1039/C5DT00556F 
Satinsky, B. M., Smith, C. B., Sharma, S., Landa, M., Medeiros, P. M., Coles, V. J., et al. (2017). Expression patterns of elemental cycling genes in the Amazon River Plume. ISME J. 11, 1852-1864. doi: 10.1038/ismej.2017.46

Schneider, S., Sharp, K. H., Barker, P. D., and Paoli, M. (2006). An induced fit conformational change underlies the binding mechanism of the heme transport proteobacteria-protein HemS. J. Biol. Chem. 281, 32606-32610. doi: 10.1074/ jbc.M607516200

Shi, L., Fredrickson, J. K., and Zachara, J. M. (2014). Genomic analyses of bacterial porin-cytochrome gene clusters. Front. Microbiol. 5:657. doi: 10.3389/fmicb. 2014.00657

Skaar, E. P., Gaspar, A. H., and Schneewind, O. (2004). IsdG and IsdI, hemedegrading enzymes in the cytoplasm of Staphylococcus aureus. J. Biol. Chem. 279, 436-443. doi: 10.1074/jbc.M307952200

Smith, J. L. (2004). The physiological role of ferritin-like compounds in bacteria. Crit. Rev. Microbiol. 30, 173-185. doi: 10.1080/1040841049043 5151

Steinegger, M., and Söding, J. (2017). MMseqs2 enables sensitive protein sequence searching for the analysis of massive data sets. Nat. Biotechnol. 35, 1026-1028. doi: $10.1038 /$ nbt.3988

Stiefel, A., Mahren, S., Ochs, M., Schindler, P. T., Enz, S., and Braun, V. (2001). Control of the Ferric Citrate Transport System of Escherichia coli: mutations in Region 2.1 of the FecI Extracytoplasmic-Function Sigma Factor Suppress Mutations in the FecR Transmembrane Regulatory Protein. J. Bacteriol. 183, 162-170. doi: 10.1128/JB.183.1.162-170.2001

Suits, M. D., Jaffer, N., and Jia, Z. (2006). Structure of the Escherichia coli O157:H7 heme oxygenase ChuS in complex with heme and enzymatic inactivation by mutation of the heme coordinating residue His-193. J. Biol. Chem. 281, 36776-36782. doi: 10.1074/jbc.M607684200

Suzuki, K., Tanabe, T., Moon, Y. H., Funahashi, T., Nakao, H., Narimatsu, S., et al. (2006). Identification and transcriptional organization of aerobactin transport and biosynthesis cluster genes of Vibrio hollisae. Res. Microbiol. 157, 730-740. doi: 10.1016/j.resmic.2006.05.001

Suzuki, R., and Shimodaira, H. (2006). Pvclust: an R package for assessing the uncertainty in hierarchical clustering. Bioinformatics 22, 1540-1542. doi: 10 . 1093/bioinformatics/btl117

Suzuki, S., Ishii, S., Hoshino, T., Rietze, A., Tenney, A., Morrill, P. L., et al. (2017). Unusual metabolic diversity of hyperalkaliphilic microbial communities associated with subterranean serpentinization at The Cedars. ISME J. 11, 2584-2598. doi: 10.1038/ismej.2017.111

Swingley, W. D., Chen, M., Cheung, P. C., Conrad, A. L., Dejesa, L. C., Hao, J., et al. (2008). Niche adaptation and genome expansion in the chlorophyll d-producing cyanobacterium Acaryochloris marina. Proc. Natl. Acad. Sci. U.S.A. 105, 2005-2010. doi: 10.1073/pnas.0709772105

Tamm, L. K., Hong, H., and Liang, B. (2004). Folding and assembly of $\beta$-barrel membrane proteins. Biochim. Biophys. Acta Biomembr. 1666, 250-263. doi: 10.1016/j.bbamem.2004.06.011

Tan, W., Verma, V., Jeong, K., Kim, S. Y., Jung, C. H., Lee, S. E., et al. (2014). Molecular characterization of vulnibactin biosynthesis in Vibrio vulnificus indicates the existence of an alternative siderophore. Front. Microbiol. 5:1. doi: 10.3389/fmicb.2014.00001

Tanabe, T., Funahashi, T., Nakao, H., Miyoshi, S., Shinoda, S., and Yamamoto, S. (2003). Identification and characterization of genes required for biosynthesis and transport of the siderophore vibrioferrin in Vibrio parahaemolyticus. J. Bacteriol. 185, 6938-6949. doi: 10.1128/JB.185.23.6938-6949. 2003

TheUniProtConsortium. (2017). UniProt: the universal protein knowledgebase. Nucleic Acids Res. 45, D158-D169. doi: 10.1093/nar/gkw1099

Tong, Y., and Guo, M. (2009). Bacterial heme-transport proteins and their hemecoordination modes. Arch. Biochem. Biophys. 481, 1-15. doi: 10.1016/j.abb. 2008.10.013

Touati, D. (2000). Iron and oxidative stress in bacteria. Arch. Biochem. Biophys. 373, 1-6. doi: 10.1006/abbi.1999.1518

Toulza, E., Tagliabue, A., Blain, S., and Piganeau, G. (2012). Analysis of the global ocean sampling (GOS) project for trends in iron uptake by surface ocean microbes. PLoS One 7:e30931. doi: 10.1371/journal.pone.0030931

Troxell, B., and Hassan, H. M. (2013). Transcriptional regulation by ferric uptake regulator (Fur) in pathogenic bacteria. Front. Cell. Infect. Microbiol. 3:59. doi: $10.3389 /$ fcimb. 2013.00059
Tullius, M. V., Harmston, C. A., Owens, C. P., Chim, N., Morse, R. P., McMath, L. M., et al. (2011). Discovery and characterization of a unique mycobacterial heme acquisition system. Proc. Natl. Acad. Sci. U.S.A. 108, 5051-5056. doi: 10.1073/pnas.1009516108

Tully, B. J., Graham, E. D., and Heidelberg, J. F. (2018). The reconstruction of 2,631 draft metagenome-assembled genomes from the global oceans. Sci. Data 5:170103. doi: 10.1038/sdata.2017.203

Uebe, R., and Schuler, D. (2016). Magnetosome biogenesis in magnetotactic bacteria. Nat. Rev. Microbiol. 14, 621-637. doi: 10.1038/nrmicro.2016.99

Wang, F. B., Gu, Y. Q., O’Brien, J. P., Yi, S. M., Yalcin, S. E., Srikanth, V., et al. (2019). Structure of microbial nanowires reveals stacked hemes that transport electrons over micrometers. Cell 177, 361.e-369.e. doi: 10.1016/j.cell.2019. 03.029

Wang, P., Lutton, A., Olesik, J., Vali, H., and Li, X. (2012). A novel iron- and copper-binding protein in the Lyme disease spirochaete. Mol. Microbiol. 86, 1441-1451. doi: 10.1111/mmi.12068

Wang, R. K., Kaplan, A., Guo, L. H., Shi, W. Y., Zhou, X. D., Lux, R., et al. (2012). The Influence of Iron availability on human salivary microbial community composition. Microbial. Ecol. 64, 152-161. doi: 10.1007/s00248-012-0013-12

Wang, S., Wu, Y., and Outten, F. W. (2011). Fur and the novel regulator YqjI control transcription of the ferric reductase gene yqjH in Escherichia coli. J. Bacteriol. 193, 563-574. doi: 10.1128/JB.01062-1010

Ward, L. M., Idei, A., Nakagawa, M., Ueno, Y., Fischer, W. W., and McGlynn, S. E. (2019). Geochemical and metagenomic characterization of Jinata Onsen, a Proterozoic-analog hot spring, reveals novel microbial diversity including iron-tolerant phototrophs and thermophilic lithotrophs. bioRxiv [pre print]. doi: 10.1101/428698,

Ward, L. M. (2017). Microbial Evolution and Rise of Oxygen: the Roles of Contingency and Context in Shaping the Biosphere through Time. Thesis Ph.D. California Institute of Technology, Pasadena, CA.

Weber, K. A., Urrutia, M. M., Churchill, P. F., Kukkadapu, R. K., and Roden, E. E. (2006). Anaerobic redox cycling of iron by freshwater sediment microorganisms. Environ. Microbiol. 8, 100-113. doi: 10.1111/j.1462-2920. 2005.00873.x

Weber, T., Blin, K., Duddela, S., Krug, D., Kim, H. U., Bruccoleri, R., et al. (2015). AntiSMASH 3.0-a comprehensive resource for the genome mining of biosynthetic gene clusters. Nucleic Acids Res. 43, W237-W243. doi: 10.1093/ nar/gkv437

Weinberg, E. D. (1978). Iron and Infection. Microbiol. Rev. 42, 45-66.

Weiss, J. V., Rentz, J. A., Plaia, T., Neubauer, S. C., Merrill-Floyd, M., Lilburn, T., et al. (2007). Characterization of neutrophilic Fe(II)-oxidizing bacteria isolated from the rhizosphere of wetland plants and description of Ferritrophicum radicicola gen. nov. sp. nov., and Sideroxydans paludicola sp. nov. Geomicrobiol. J. 24, 559-570. doi: 10.1080/01490450701670152

Welch, J. L. M., Rossetti, B. J., Rieken, C. W., Dewhirst, F. E., and Borisy, G. G. (2016). Biogeography of a human oral microbiome at the micron scale. Proc. Nal. Acad. Sci. U.S.A. 113, E791-E800. doi: 10.1073/pnas.1522149113

Wertheimer, A. M., Verweij, W., Chen, Q., Crosa, L. M., Nagasawa, M., Tolmasky, M. E., et al. (1999). Characterization of the angR gene of Vibrio anguillarum: essential role in virulence. Infec.t Immun. 67, 6496-6509.

White, G. F., Edwards, M. J., Gomez-Perez, L., Richardson, D. J., Butt, J. N., and Clarke, T. A. (2016). Mechanisms of Bacterial Extracellular Electron Exchange. Amsterdam: Elsevier Ltd.

Wickham, H. (2007). Reshaping data with the reshape package. J. Stat. Softw. 21, 1-20. doi: 10.3978/j.issn.2305-5839.2016.01.33

Wickham, H. (2009). Ggplot2: Elegant Graphics for Data Analysis. New York, NY: Springer-Verlag.

Wickham, H. (2017). Tidyverse: Easily Install and Load the 'Tidyverse'. R package version 1.2.1. Available at: https://cran.r-project.org/web/packages/tidyverse/ index.html.

Wilks, A., and Heinzl, G. (2014). Heme oxygenation and the widening paradigm of heme degradation. Arch. Biochem. Biophys. 544, 87-95. doi: 10.1016/j.abb.2013. 10.013

Wilson, M. C., Mori, T., Ru, C., and Matsunaga, S. (2014). An environmental bacterial taxon with a large and distinct metabolic repertoire. Nature 506, 58-62. doi: 10.1038/nature12959

Wójtowicz, H., Guevara, T., Tallant, C., Olczak, M., Sroka, A., Potempa, J., et al. (2009). Unique structure and stability of HmuY, a novel heme-binding protein 
of Porphyromonas gingivalis. PLoS Pathog 5:e1000419. doi: 10.1371/journal. ppat.1000419

Wyckoff, E. E., Mey, A. R., Leimbach, A., Fisher, C. F., and Payne, S. M. (2006). Characterization of ferric and ferrous iron transport systems in Vibrio cholerae. J. Bacteriol. 188, 6515-6523. doi: 10.1128/JB.00626-626

Wyckoff, E. E., Smith, S. L., and Payne, S. M. (2001). VibD and VibH are required for late steps in vibriobactin biosynthesis in Vibrio cholerae. J. Bacteriol. 183, 1830-1834. doi: 10.1128/JB.183.5.1830-1834.2001

Wyckoff, E. E., Valle, A. M., Smith, S. L., and Payne, S. M. (1999). A multifunctional ATP-binding cassette transporter system from Vibrio cholerae transports vibriobactin and enterobactin. J. Bacteriol. 181, 7588-7596. doi: 10.1128/jb.181. 24.7588-7596.1999

Youard, Z. A., Wenner, N., and Reimmann, C. (2011). Iron acquisition with the natural siderophore enantiomers pyochelin and enantio-pyochelin in Pseudomonas species. Biometals 24, 513-522. doi: 10.1007/s10534-010-93999399
Zhang, R., Zhang, J., Guo, G., Mao, X., Tong, W., Zhang, Y., et al. (2011). Crystal structure of Campylobacter jejuni ChuZ: a split-barrel family heme oxygenase with a novel heme-binding mode. Biochem. Biophys. Res. Commun. 415, 82-87. doi: 10.1016/j.bbrc.2011.10.016

Conflict of Interest: The authors declare that the research was conducted in the absence of any commercial or financial relationships that could be construed as a potential conflict of interest.

Copyright $(2020$ Garber, Nealson, Okamoto, McAllister, Chan, Barco and Merino. This is an open-access article distributed under the terms of the Creative Commons Attribution License (CC BY). The use, distribution or reproduction in other forums is permitted, provided the original author(s) and the copyright owner(s) are credited and that the original publication in this journal is cited, in accordance with accepted academic practice. No use, distribution or reproduction is permitted which does not comply with these terms. 